This item was submitted to Loughborough's Research Repository by the author.

Items in Figshare are protected by copyright, with all rights reserved, unless otherwise indicated.

\title{
Effects of material, coating, design and plaque composition on stent deployment inside a stenotic artery-finite element simulation
}

PLEASE CITE THE PUBLISHED VERSION

http://dx.doi.org/10.1016/j.msec.2014.05.057

\section{PUBLISHER}

(C) Elsevier B.V.

\section{VERSION}

AM (Accepted Manuscript)

\section{PUBLISHER STATEMENT}

This work is made available according to the conditions of the Creative Commons Attribution-NonCommercialNoDerivatives 4.0 International (CC BY-NC-ND 4.0) licence. Full details of this licence are available at: https://creativecommons.org/licenses/by-nc-nd/4.0/

\section{LICENCE}

CC BY-NC-ND 4.0

\section{REPOSITORY RECORD}

Schiavone, Alessandro, Liguo Zhao, and Adel A. Abdel-Wahab. 2014. "Effects of Material, Coating, Design and Plaque Composition on Stent Deployment Inside a Stenotic Artery-finite Element Simulation”. Loughborough University. https://hdl.handle.net/2134/16950. 


\title{
Effects of Material, Coating, Design and Plaque Composition on
}

\section{Stent Deployment inside a Stenotic Artery - Finite Element}

\section{Simulation}

\author{
A Schiavone, LG Zhao*, AA Abdel-Wahab \\ Wolfson School of Mechanical and Manufacturing Engineering, Loughborough \\ University, LE11 3TU, Loughborough, UK
}

*Corresponding author: Dr Liguo Zhao; Email: L.Zhao@LLboro.ac.uk; Tel: 0044-1509-

227799; Fax: 0044-1509-227648.

\begin{abstract}
Finite-element simulations have been carried out to study the effects of material choice, drug eluting coating and cell design on the mechanical behaviour of stents during deployment inside a stenotic artery. Metallic stents made of materials with lower yield stress and weaker strain hardening tend to experience higher deformation and stronger dogboning and recoiling, but less residual stresses. Drug eluting coatings have limited effect on stent expansion, recoiling, dogboning and residual stresses. Stent expansion is mainly controlled by the radial stiffness of the stent which is closely associated with the stent design. In particular, open-cell design tends to have easier expansion and higher recoiling than closed-cell design. Dogboning is stronger for slotted tube design and open-cell sinusoidal design, but reduced significantly for designs strengthened with longitudinal connective struts. After deployment, the maximum von Mises stress appears to locate at the U-bends of stent cell struts, with varying magnitude that depends on the materials and severity of plastic deformation. For the artery-plaque system, the stresses,
\end{abstract}


especially in the plaque which is in direct contact with the stent, appear to be distinctly different for different stent designs and materials in terms of both distribution and magnitude. The plaque composition also strongly affects the expansion behaviour of the stent-artery system and modifies the stresses on the plaque.

Keywords: Stent expansion; Stenotic artery; Finite element; Recoiling; Dogboning; Stresses.

\section{Introduction}

Engineering aspects of stent design involve geometry optimisation, material selection and coating technology (Sangiorgi et al., 2007). According to Hanawa (2009), stainless steel is the most commonly used material for stents, while alternatives include shape-memory alloy nitinol, tantalum, cobalt-chromium (Co-Cr) alloys, magnesium (Mg) alloys and biodegradable polymers. For geometry, early designs were generally classified as either slotted tube geometries, such as the Palmaz-Schatz stents, or coil geometries, such as the Gianturco-Roubin Flex stent. Slotted-tube type designs had excellent radial strength but they lacked flexibility; while the opposite occurred for coil designs. The subsequent evolution of stent design yielded the development of a rich variety of stent geometries, which can be classified into five main categories: coil, helical spiral, woven and rings (Sangiorgi et al., 2007). The majority of commercially available stents can be generally divided into two groups, i.e., closed cell and open cell design, with different types of connection such as peak to peak or valley to valley. Besides the scaffold structure, modern stents tend to have drug eluting coatings which are particularly used to treat instent restenosis, i.e., re-narrowing of blood vessels after stent implantation (Khan et al., 2012). 
Finite element method has been widely employed to assess the biomechanical behaviour of stents by modelling their free expansion as well as deployment in diseased arteries. Migliavacca et al. (2005) modelled the free expansion of a coronary stent named Cordis BX Velocity, and the central radial elastic recoil, obtained from experiments and simulations, was close to each other at a certain level of expansion or inflating pressure. A study of a Genesis stent made of stainless steel, aiming to determine the diameter change as a function of inflating pressure during free expansion, was conducted by Walke et al. (2005) using computational methods. The results showed that the process of stent enlargement is not proportional to the pressure inside the balloon. A sudden increase of the stent diameter was observed after exceeding a critical value of the balloon pressure, which is in good agreement with the experimental data. For stent deployment, Chua et al. (2004) simulated the expansion of a Palmaz-Schatz stent inside an artery with stenotic plaque. The results demonstrated the capability of slotted-tube stents in resisting the recoil of blood vessel and preventing restenosis after expansion. Lally et al. (2005) carried out a comparative study of two stents (i.e. S7 and NIR stents) by simulating their deployment inside a stenotic artery. Their results showed that the S7 stent caused lower stress on the blood vessel wall compared to the NIR, which was consistent with clinical observations that the NIR stent has a higher restenosis rate than S7. So far, majority computational studies are limited to a specific stent and a specific material, a detailed comparative study across all generations of stents is lacking, especially the effects of key stent design features and material choices on their biomechanical behaviour.

Although drug eluting stents have been dominantly used in the current clinical treatment of stenosis, very limited research has actually been carried out to study the mechanical behaviour of drug eluting coatings (existing work mainly focused on drug release), particularly how they influence the process of stent deployment. In our literature survey, 
we came across only two papers which investigated the coating effect. For instance, Gu et al. (2005) modelled the influence of silicone coating during the deployment of a microstent in an artery with long fusiform aneurysm. It was shown that the coated stent needed an appreciatively 30\% higher pressure to expand the artery to same extent as its bare metal version, where the coating and the strut had the same thickness $(0.1 \mathrm{~mm})$. While Hopkins et al. (2010) investigated the two-dimensional delamination of the stent coating during deployment, which occurred mainly in the region of hinge with high plastic deformation. The initiation of coating debonding depended on the coating thickness, the coating material and the curvature of the hinge.

Recently, a number of medical case reports showed that stent implants may lead to restenosis (Okamura et al., 2008), myocardial infarction (Park et al., 2009), thrombosis (Choe et al., 2009) and unstable angina (Adlakhna et al., 2009). It was also frequently reported that stent failure might happen at any time, which can cause thrombosis, restenosis, pain and other clinical complications in patients (Kim et al., 2009; Umeda et al., 2009; Celik et al., 2009). If diagnosed with stent failure, patients will need to undergo further surgery to remove the failed stent and implant a new one to solve the problem. To reduce the risk of complications associated with stenting, it is important to implant the most suitable stent for the patient, for which it is necessary to have a thorough understanding of the biomechanical behaviour of stents with different designs, materials and coatings. In addition, stent deployment can be affected by the plaque composition, such as calcified and hypocellular plaques, due to their very different mechanical behaviour (Loree et al., 1994). A study of such effect will help cardiologists to choose the most suitable stent type to control the plaque rupture during and after stenting. This is the motivation behind this research paper. 
In this paper, finite element analyses have been carried out to simulate the deployment of Xience stent (Abbott Laboratories, USA), one of the latest commercial stents, inside a stenotic artery. The essential performances (e.g. expansion, dogboning and recoiling) of the stent were evaluated first, especially the effects of material choice and stent coating. Effect of stent designs on the behaviour is studied through comparison with three other typical stents, Palmaz-Schatz (Palmaz Scientific, USA), Cypher (Cordis Corporation, USA) and Endeavor (Medtronic, USA), representing the stents of three generations. Furthermore, this paper also investigated the stresses on the artery/plaque system, which has a close connection with in-stent restenosis, and the effect of plaque composition on stent deployment.

\section{Finite Element Simulation}

\subsection{Geometrical models}

Models of Xience stent, as well as Palmaz-Schatz, Cypher and Endeavor stents, were produced using Simulia Abaqus CAE (Abaqus, 2013) according to the geometries reported in open resources. The length of all stents was chosen to be $10 \mathrm{~mm}$ and the diameter at the crimpled state was fixed at $1.5 \mathrm{~mm}$. The strut thickness is $120 \mu \mathrm{m}, 140 \mu \mathrm{m}$, $80 \mu \mathrm{m}$ and $90 \mu \mathrm{m}$ for Palmaz-Schatz, Cypher, Xience and Endeavor, respectively. Xience stent was chosen to investigate the effects of three typical materials, i.e., stainless steel, cobalt-chromium alloy and magnesium alloy, on stent expansion inside a diseased artery. To study the coating effect, a thin layer of polymer $(8 \mu \mathrm{m})$ was applied to Xience stent and assumed to be perfectly bonded to the stent platform. All stents are balloon expandable. The balloon was modelled as a cylinder with a diameter that matched the inner diameter of the stent. The balloon is $2 \mathrm{~mm}$ longer than the stent (i.e. one millimetre longer at each end). The blood vessel was modelled as a cylinder with axisymmetric stenotic plaque. The artery has a length of $20 \mathrm{~mm}$ and a wall thickness of $1 \mathrm{~mm}$, while the 
plaque has a length of $10 \mathrm{~mm}$ and a maximum thickness of $0.75 \mathrm{~mm}$ (middle section). The inner diameter for the healthy artery and the stenotic plaque (middle section) is $4 \mathrm{~mm}$ and $2.5 \mathrm{~mm}$ respectively. The artery was considered to consist of three tissue layers, i.e., intima, media and adventitia, with a thickness of $0.27 \mathrm{~mm}, 0.35 \mathrm{~mm}$ and $0.38 \mathrm{~mm}$, respectively. The interfaces between different vessel layers were assumed to be coherent, and treated as perfectly bonded, which is also the case for the interface between the artery wall and the stenotic plaque.

\subsection{Finite Element Mesh}

Using Abaqus CAE (Abaqus, 2013), stents were meshed into first order incompatible brick elements (C3D8I), with four layers of elements through the thickness of the stent strut and two layers of elements through the width of the stent strut. The mesh consists of 50,000 100,000 elements, depending on the type of stent. The incompatible brick elements (with full integration) were particularly used to accommodate large bending deformation of the stent strut. This is also strongly recommended by Abaqus for stent deformation simulation (Abaqus, 2013). The balloon was meshed using hexahedral elements with reduced integration (C3D8R), and the number of elements was $\sim 10,000$ for all simulations. The artery wall was also meshed using hexahedral elements (C3D8R, reduced integration), with two layers of elements through the thickness of each vessel layer. The plaque was meshed using hexahedral elements (C3D8R, reduced integration), with four layers of elements through the thickness. The artery and plaque system has about 20,000 elements in total. The generated mesh is shown in Figure 1 for a Xience stent and the stenotic artery (with balloon). Mesh sensitivity study has also been carried out, and confirmed the convergence of the results, in terms of stent diameter change, recoiling effect and residual stresses, for the mesh used in the present paper. 


\subsection{Materials and Constitutive Models}

316L stainless steel is the material used to manufacture the Palmaz-Schatz and Cypher stents, while Co-Cr alloys are used for Xience (type L605) and Endeavor (type F562) stents. In addition, Magnesium alloy AZ31 was also considered to study the effect of materials on stent deployment. The three materials were all modelled using the elasticplastic stress-strain relationship with nonlinear hardening behaviour as given in Figure 2a (Poncin et al., 2003; Wu et al., 2010). The stress-strain curves in Figure 2a are the tensile test data for stent materials, which were implemented in Abaqus by considering the increase of yield stress as a function of plastic strain (Abaqus, 2013). The stent coating was made of Phosphorylcholine (PC) polymer with bilinear behaviour and the parameter values are given in Table 1 (Hopkins et al., 2010).

The balloon was modelled using a Mooney-Rivlin hyperelastic strain energy potential W (Mooney, 1940; Rivlin 1948):

$$
\begin{aligned}
& \mathrm{W}=\mathrm{C}_{10}\left(\mathrm{I}_{1}-3\right)+\mathrm{C}_{01}\left(\mathrm{I}_{2}-3\right)+\frac{1}{\mathrm{D}_{1}}(\mathrm{~J}-3) \\
& \mathrm{I}_{1}=\lambda_{1}^{2}+\lambda_{2}^{2}+\lambda_{3}^{2} \\
& \mathrm{I}_{2}=\lambda_{1}^{2} \lambda_{2}^{2}+\lambda_{2}^{2} \lambda_{3}^{2}+\lambda_{1}^{2} \lambda_{3}^{2}
\end{aligned}
$$

where $\lambda_{\mathrm{i}}(\mathrm{i}=1,2,3)$ are the stretches in the three principal directions, $\mathrm{J}$ is the volumetric stretch, $\mathrm{C}_{10}(\mathrm{MPa}), \mathrm{C}_{01}(\mathrm{MPa})$ and $\mathrm{D}_{1}$ are model coefficients. Physically, $\mathrm{C}_{10}$ is associated with the stiffness of the material in the stretch mode, $\mathrm{C}_{01}$ refers to the stiffness in the shear mode and $\mathrm{D}$ represents the compressibility of the material. Table 2 lists the values of the corresponding parameters (Chua, 2002; Chua et al., 2004), where $\mathrm{D}_{1}=0$ means that the material was considered incompressible.

Both the blood vessel and stenotic plaque were described by Ogden hyperelastic strain energy potential (Zahedmanesh and Lally, 2009; Zahedmanesh et al., 2010): 


$$
W=\sum_{i=1}^{3} \frac{2 \mu_{i}}{\alpha_{i}^{2}}\left(\lambda_{1}^{\alpha_{i}}+\lambda_{2}^{\alpha_{i}}+\lambda_{3}^{\alpha_{i}}-3\right)+\sum_{i=1}^{3} \frac{1}{D_{i}}(J-1)^{2 i}
$$

where $\mu_{\mathrm{i}}(\mathrm{MPa}), \alpha_{\mathrm{i}}$ and $\mathrm{D}_{\mathrm{i}}$ are model parameters. The values of the coefficients in Eq (2) are given in Table 3 (Zahedmanesh and Lally, 2009). Physically, $\mu_{\mathrm{I}}$ and $\alpha_{\mathrm{i}}$ describe the shear behaviour of the material and $\mathrm{D}_{\mathrm{i}}$ represents the compressibility (Ali et al., 2010). The model parameters were fitted by Zahedmanesh and Lally (2009) using the test data in Holzapfel (2005) for arterial layers and Loree et al. (1994) for hypocellular plaque. The arterial layers and the plaque were assumed to be nearly incompressible. This assumption was realised by specifying a Poisson's ratio of 0.49 for the material and infinitesimal values for $D_{1}\left(D_{2}=D_{3}=0\right)$. Using the above hyperelastic formulations, the corresponding stress-strain curves were computed and compared in Figure $2 \mathrm{~b}$ for these tissues.

Mooney-Rivlin model has also been widely used to describe the constitutive behaviour of blood vessel. The difference between Mooney-Rivlin and Ogden models is just the type of formulation for strain energy potential (Prendergast et al., 2003; Gastaldi et al., 2010; Zahedmanesh and Lally, 2009; Karimi et al., 2014). We have compared the simulations using the Ogden model and the Mooney-Rivlin model, and the two models gave very similar results of stent expansion behaviour. The reason that we chose the Ogden model is the availability of full model parameters for all three vessel layers (Zahedmanesh and Lally, 2009), and also the model capability has been verified against a proper set of experimental data including both uniaxial and circumferential loading conditions (Loree et al., 1994; Holzapfel et al., 2005).

\subsection{Loading and constraints}


A uniform and linearly increasing pressure was applied to the inner surface of the balloon to simulate the inflation process, followed by deflation (pressure decreased to zero linearly). The applied pressure is between $1.4 \sim 1.6 \mathrm{MPa}$, depending on the radial stiffness of the stents as well as the deformability of the stent/artery systems. Specifically, $1.4 \mathrm{MPa}$ was used for Xience and Endeavor stents while 1.5MPa and 1.6MPa were used for Cypher and Palmaz-Schatz stents, respectively. Both inflation and deflation times were chosen to be 0.1 second. In all simulations, the ends of the balloon were fully constrained as is in the real situation (fixed onto catheter), and the ends of the blood vessel were also fixed to reflect the constraint from the human body environment. Interactions between the balloon, the stent and the blood vessel were modelled as surface to surface hard contacts, with a frictional coefficient of 0.25 (Ju et al., 2008).

\subsection{Post-processing of results}

Abaqus explicit has been used to carry out all the simulations, with controlled time increments (Abaqus, 2013). The time increment was on the order of $10^{-8} \mathrm{~s}$ throughout the analysis. The internal and kinetic energies have been monitored during the analyses, and the kinetic energy for whole the system was always less than 5\% of the internal energy, which confirmed the validity of our quasi-static analyses. Also, Abaqus used enhanced hourglass control approach for the hyperelastic materials (i.e. artery, plaque and balloon), which provides resistance to hour glassing. For the stent, full integration elements were used and hour glassing was not encountered.

The coordinates of three nodes on the stent (i.e., one in the middle and two at the ends) were particularly tracked and used to determine the dogboning and recoiling effects. The dogboning effect was calculated using the following equation: 


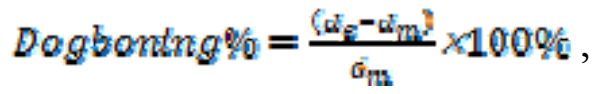

where $d_{e}$ is the mean diameter at the ends of the stent and $d_{m}$ the diameter in the middle of the stent after deflation. The recoiling effect was calibrated from the tracked coordinates of the node in the middle of stent using the following equation:

$$
\text { Recotthg } \%=\frac{\left(w_{n}-w_{2}\right)}{\omega_{0}} \times 100 \%
$$

where $d_{0}$ is the diameter in the middle of the stent at maximum pressure and $d_{1}$ is the diameter in the middle of the stent after deflation. Besides, the stresses for the whole system (both the stent and the artery/plaque) were also obtained to evaluate the mechanics of both stent and artery/plaque during the full process of stent deployment.

Validation of the modelling approach was carried out by comparing our simulations of Palmaz-Schatz stent expansion, including both free expansion and deployment in a stenotic artery, against those in Chua et al. (2003; 2004). Good agreements were obtained for stent expansion and stress distributions, which confirmed the validity of the general method used in the present paper.

\section{Results and Discussion}

\subsection{Expansion behaviour of Xience stent}

Figure 3 a shows the change of diameter against the pressure, applied inside the balloon, for Xience stent and the artery during the process of deployment inside a diseased artery. Expansion was shown to have three stages. At the initial stage (up to $0.8 \mathrm{MPa}$ ), stent deforms elastically and has a lower rate of expansion. Beyond $0.8 \mathrm{MPa}$ pressure, plastic deformation occurs and stent seems to expand steadily, together with the artery, at a fairly constant rate $(9 \mathrm{~mm} / \mathrm{MPa})$. At a pressure of $1.1 \mathrm{MPa}$, the rate of stent expansion starts to decrease drastically, indicating that the deformation of the stent/artery system 
seems to reach a saturation stage, i.e., further increase of pressure only results in very limited expansion. This is mainly due to the intrinsic deformation behaviour of the artery which reached a saturation stage of stretch at a pressure of $1.1 \mathrm{MPa}$, especially the intima layer (see Fig.2b). Consequently, the system becomes considerably resistant to further expansion, resulting in a drastic decrease of expansion rate. Overall, stent expanded from $1.5 \mathrm{~mm}$ to $4.8 \mathrm{~mm}$ at the maximum pressure $(1.4 \mathrm{MPa})$, with an increase in diameter by more than three fold. During deflation, recovered elastic deformation and radial pressure from the viscoelastic artery system lead to the recoil of the stent, but stabilised at $3.7 \mathrm{~mm}$ which is close to the diameter of a healthy artery. The achieved expansion was calculated to be $52 \%$ for the diseased artery. Recoiling and dogboning effects after deflation were calculated to be $22 \%$ and $17 \%$, respectively (see Figure $5 \mathrm{~b}$ for Co-Cr L605 stent). The development of both dogboning and recoiling effects is plotted in Figure $3 \mathrm{~b}$ during the deflation process. It is noted that dogboning has a "negative" value at the end of inflation, which is due to the more severe expansion at the middle section of the stent. This also led to much more severe stretch for middle part of the artery-plaque system. As a result, during deflation the severely stretched artery at the middle part has a stronger tendency to recover its hyperelastic deformation, which forced the stent to recoil more at the middle section, leading to the "dogboning" effect at the end of deflation process. The development of recoiling is a continuous process due to the elastic recovery of stretched artery-plaque systems (Figure 3b).

Analyses were also carried out to simulate the stent expansion by multiple inflations of the balloon, which has been used in clinical practice to enhance the expansion of the stenotic artery. In our simulations, the whole process was split into six inflation-deflation (loading-unloading) steps, occurring at $65 \%, 70 \%, 75 \%, 80 \%, 85 \%$ and $100 \%$ of the total applied pressure, respectively. The monitored diameter change is plotted in Figure 4, with 
a direct comparison against the single-step simulation. Our results suggested that the final diameter achieved is quite sensitive to the multiple inflation method, and the blocked artery achieved a larger diameter $(4.2 \mathrm{~mm})$ than the single-inflation method $(3.7 \mathrm{~mm})$ for a given pressure due to the enhanced plastic deformation associated with cyclic hardening.

\subsection{Effect of materials on stent expansion}

Three materials, Co-Cr L605, SS316L and Mg alloy AZ31, which are mainly used for stent fabrication, were considered to study the effect of materials on stent expansion. Results showed that the material choice has an influence on the behaviour of expansion (Figure 5a). Stents made of $\mathrm{Mg}$ alloy AZ31 and SS316L tend to experience higher deformation, compared to Co-Cr L605 stent, exhibiting less radial stiffness. Also, the dogboning and recoiling effects appear to be higher for stent made of stainless steel and Mg alloy (Figure 5b).

Figure 6 compares the von Mises stress distribution on the stent for the three materials following stent deployment. The stent has severe stress concentrations at the U-bends of the cell struts due to highly localised stretch. These are residual stresses which were developed due to the sustained plastic deformation. From the computed results, it appears that the material choice has an impact on the magnitudes of the maximum von Mises stress on the stent. Stent made of $\mathrm{Mg}$ alloy has a significantly lower value $(\sim 425 \mathrm{MPa})$ than those made of Co-Cr L605 and SS316L (>700MPa). These results are in line with the stress-strain behaviour of the three materials, i.e. higher Young's modulus and stronger strain hardening for Co-Cr L605 alloy and SS316L (Figure 2a). For Co-Cr L605 stent, the magnitude of residual stress was shown to be around $778 \mathrm{MPa}$ (see Figure 6), which is very significant and implies the potential risk of failure during stent 
employment. Consequently, optimal design of cell strut U-bends appears to be important for modern stents, which can lead to stress reduction and failure resistance. However, it should be noted that in reality, the stresses on the stents might not reach such high magnitude if the residual stresses developed during stent crimping (Möller et al., 2001; Kleinstreuer et al., 2008; Shankaran et al., 2012) are considered which shall mitigate the stresses developed during stent expansion.

\subsection{Effect of coating on stent expansion}

Fully coated Xience stent was simulated to study the influence of stent coating on stent expansion inside a stenotic artery. Figure 7 a shows the diameter change during expansion process, in a comparison with that for uncoated one. The maximum diameter reached $4.8 \mathrm{~mm}$ in both simulations, but the coated stent recoiled slightly less $(20.6 \%$ against $21.8 \%$ ) due to the coating constraint (Figure 7b). However, the dogboning is slightly higher for coated stent (19.5\%) compared to bare metal one (17.7\%), as shown in Figure 7b. Results suggest that drug eluting coatings has little effect on stent expansion (i.e. radial stiffness), but reduces recoil effect and increase dogboning effect slightly. For both cases, the maximum von Mises stress was located at the U-bends of the cell struts, as shown in Figure 8. The coated stent had a higher residual stress level (793.6MPa) compared to the bare metal stent $(778.4 \mathrm{MPa})$. The increase of stress level on the coated stent is due to property mismatch between the stent and the coating, which generally leads to delamination as observed in experiments, particularly in the U-bend regions (Hopkins et al., 2010).

The work of $\mathrm{Gu}$ et al. (2005) showed that the required deployment pressure increases almost linearly with the thickness of coating. For a $0.1 \mathrm{~mm}$ thick coating, the coated stent needed an appreciatively 30\% higher pressure to expand the artery to the same extent as 
its bare metal version. But it should be noted that, in their simulations, the coating thickness (varying between $0.08 \mathrm{~mm} \sim 0.15 \mathrm{~mm}$ ) is comparable to, and even larger than, the thickness of strut (only $0.1 \mathrm{~mm}$ ). In our work, the coating thickness $(8 \mu \mathrm{m})$ is only $10 \%$ of the strut thickness $(80 \mu \mathrm{m})$ for the commercial Xience stent. Consequently, no significant effect of coating on stent expansion was observed in our computational simulations due to the relatively thin coating layer. To study the effects of coating thickness and modulus on stent expansion, simulations have been carried out for a tworing stent model (to save computing time), with varying coating thickness $(8 \mu \mathrm{m} \sim 12 \mu \mathrm{m})$ and modulus (two and five times the value used above). The effects on stent expansion and recoiling were found negligible for the ranges of coating thickness and modulus considered. Further work is ongoing to simulate the whole stent model with wider ranges of coating thickness and modulus.

\subsection{Comparative study of four stents - effect of designs on stent expansion}

Figure 9a shows the change of diameter against the pressure, applied inside the balloon, for four stents, e.g. Palmaz-Schatz, Cypher, Xience and Endeavour, during expansion inside a diseased artery. Xience and Endeavor stents had similar expansion behaviour with a maximum diameter of $4.8 \mathrm{~mm}$ achieved at $1.4 \mathrm{MPa}$ pressure. They were also easier to expand due to the open cell designs. While Palmaz-Schatz and Cypher stents, which have closed cell design, required higher pressure to expand to the same extent as Xience and Endeavor. For instance, the pressure required to reach a 4-mm expansion is 1.2, 1.3, 1.4 and 1.6 for Endeavor, Xience, Cypher and Palmaz-Schatz, respectively. This suggests that the diameter change is mainly controlled by the radial stiffness of the stent which is closely associated with the stent design. 
The diameter change during balloon deflation (Figure 9a) appeared to be distinctly different for the four stents. This is also clearly reflected in the recoiling and dogboning effects as shown in Figure 9b. Palmaz-Schatz has the least percentage of recoiling (1.6\%), followed by Cypher (5\%), Xience (21.8\%) and Endeavor (31.1\%). For dogboning, Endeavor showed the most severe effect $(36.8 \%)$ due to the high level of recoiling. Palmatz-Schatz also has a high level of dogboning (22.4\%) which is mostly developed during the inflation process as the recoiling effect is very little. Cypher and Xience exhibit less dogboning effect (10.4\% and $17.7 \%$, respectively), with mechanisms similar to those for Palmatz-Schatz and Endeavor.

Figure 10 gives the von Mises stress distribution after deflation. Again, all four stents showed severe stress concentrations at the corners or U-bends of struts, indicting the importance of U-bend design in stents. These are also the residual stresses developed during the deployment process. The peak stress level seems to be close to or even higher than the ultimate tensile strength (UTS) of the materials. Consider that the UTS is $\sim 1012 \mathrm{MPa}$ for Co-Cr alloys and $\sim 606 \mathrm{MPa}$ for stainless steel, Xience and Endeavor stents, with stresses less than UTS, seem to have a lower risk of fracture during the expansion whilst the Palmaz-Schatz and Cypher exhibit a higher risk of failure as the stress magnitudes exceeded their respective UTS values. It also appears that stents designed with enhanced flexibility (e.g. Cypher and Endeavour) exhibit lower stress levels than those designed with increased rigidity (e.g. Palmaz-Schatz and Xience). Again, material is another factor that affects the stresses on stents. For designs with similar flexibility/rigidity (e.g. Palmaz-Schatz and Xience), stents made of stainless steel tend to have relatively low stress levels due to its lower yield stress and weaker strain hardening when compared to those made of Co-Cr alloy, which agrees with the results in Section 3.2. As mentioned in Section 3.1, our simulation did not consider the residual stress 
developed during stent crimping, which might be the rational for the unrealistically high stress levels obtained in our work. Further study is ongoing to investigate this aspect thoroughly.

\subsection{Stresses on the plaque-artery system}

From our simulation, at the peak inflation pressure, the maximum von Mises stresses on the plaque-artery system were located in the intima layer of the artery with a magnitude of $6.3 \sim 11.5 \mathrm{MPa}$, due to the relatively high stiffness of the intima layer (Figure $2 \mathrm{~b}$ ) as well as the severe constraint on the intima layer imposed by surrounding tissues (Figure 1). After deflation, the maximum stress shifted to the plaque, especially at locations where the stent and the plaque are in full contact. Contour plots of the von Mises stresses on the plaque/artery after deflation are shown in Figures $11 \sim 13$ for all simulations performed in this paper. As shown in Figure 11, the magnitude is around $0.58 \mathrm{MPa}$ for arteries expanded by Co-Cr Xience stent, and reduced to $0.36 \mathrm{MPa}$ (by $\sim 40 \%$ ) and $0.29 \mathrm{MPa}$ (by $\sim 50 \%$ ) respectively, when the stent material is changed to stainless steel and $\mathrm{Mg}$ alloy, indicating a considerable influence of stent materials. As discussed earlier, stainless steel and $\mathrm{Mg}$ alloy have relatively low yield stress and weak strain hardening which soothed the mechanical interaction at the contact locations between stent and artery, and hence reduced the stress level on the artery. This reduction is also associated with the stronger recoiling effect for stainless steel and Mg alloy stents, which further relaxed the stresses on the plaque. The coating layer, which is relatively thin, seems to increase the stress on the plaque only slightly (Figure 12).

Stresses on the artery/plaque inflated by the four types of stent were compared against each other in Figure 13, which showed distinctly different behaviour in terms of both distribution and magnitude. In most cases, the stress concentration tends to occur on the 
plaque due to the direct contact of the plaque with the expanded stent. For the artery under severe stretch (e.g. Palmaz-Schatz stent), a significant amount of stress was still carried by the intima layer of the artery due to the less recovered deformation or stretch. Also the latest generation of stents (e.g. Xience and Endeavor) tend to cause less stresses on the plaque/artery than the earlier generation of stents (e.g. Palmaz-Schatz and Cypher), even if they are made of stiffer Co-Cr alloys. To elaborate this, Palmaz-Schatz and Cypher stents have completely closed-cell designs while Xience and Endeavor stents have dominantly open-cell designs (strengthened through longitudinal connections). Closed-cell designs increased the radial stiffness of stents and introduced strong interaction between stent and artery-plaque during stent deployment, leading to higher stress levels. This indicates the importance of stent designs in reducing the stresses on the artery/plaque system caused by stenting.

Recent investigations suggest that arterial wall biomechanics plays a key role in in-stent restenosis (Haga et al., 2007; Gu et al., 2010; Zhao et al., 2012). The altered solid mechanical environment following stent deployment governs the inflammatory and remodelling response of blood vessels. For instance, Timmins et al. (2011) quantified both the solid biomechanical environment and in-vivo porcine arterial response of two stent designs which impose considerably different mechanical stresses and strains on the arterial wall. Stents that induce higher nonphysiologic stresses provoke a more aggressive pathobiological response of the artery wall, resulting in a higher degree of neointimal hyperplasia. In-vitro study results have also demonstrated that mechanical stresses regulate the proliferation, apoptosis and migration of vascular cells (Haga et al., 2007), and the synthesis, degradation and reorganization of extra cellular matrix (Chung et al., 2002; Haga et al., 2007). The current study showed that the mechanical stress (0.3 4.6MPa for an applied balloon pressure of 1.4 1.6MPa) on the vessel wall 
generated by stent implantation is significantly higher than the wall shear stress $(1 \sim 2 \mathrm{~Pa}$ only, as reported by Haga et al., (2007)) generated by blood flow, and will contribute to the development of in-stent restenosis considerably. In addition, the current work also proved that the stresses in the vessel wall are highly dependent on the stent design and material choice (Fig.11 and Fig. 13). The level of artery stresses can be controlled through optimal stent design as well as material selection, which has significant implications in preventing the occurrence of in-stent restenosis.

\subsection{Effect of plaque composition}

The stenotic plaque can be modelled as hypocellular, cellular or calcified plaque depending on its composition. To study the effect of plaque composition, simulations have also been carried out for calcified plaque (cellular plaque is expected to have the behaviour in between hypocellular and calcified plaques). The calcified plaque was modelled using the Ogden model, consistent with that used for the hypocellular plaque. The model parameters given in Table 4 were fitted against the test data in Loree et al. (1994) and Pericevic et al. (2009). The stress-strain behaviour for calcified and hypocellular plaques is compared in Figure 14, showing that calcified plaque is more resistant to stretch than hypocellular plaque. The simulations were carried out for all four stent designs using exactly the same loading and boundary conditions given in Section 2. As shown in Figure 15, the calcified plaque affects the deployment by reducing the stent expansion considerably for all stent designs, with a final diameter between $3.0 \mathrm{~mm}$ and $3.3 \mathrm{~mm}$ only which is significantly lower than that for hypocellular plaque (Fig.9a). The reason is that the calcified plaque is much stiffer than the hypocellular plaque (Fig.14), which prohibited the effective expansion of the stent-artery system. The von Mises stresses on the stents were found to be similar in all cases, in terms of both distribution and magnitude. However, the maximum von Mises stress on the calcified plaque is 
always higher than that on the hypocellular plaque as compared in Figure 16, with stress concentration observed towards the ends of the calcified plaque where the stent and the plaque are in strong contact caused by the dogboning effect.

These results indicate that stent deployment also strongly depends on the composition of the stenotic plaque. Stent expansion simulated using a calcified plaque model tends to reach a saturation stage far earlier than that using a hypocellular plaque model (Fig.15). The finally achieved expansion for calcified plaque model is significantly lower than that for hypocellular plaque model, which is true for all four stent designs. However, the stresses in the artery-plaque system suggest that Xience and Endeavor stents with open cell design are less likely to cause plaque rupture, regardless of the plaque composition, due to the lower stress levels on the plaque when compared to Cypher and PalmazSchatz stents with closed cell design.

\section{Limitations of the current work}

As shown in Liu et al. (2007), the artery deformation, subjected to internal pressure, is considerably less in the presence of surrounding tissues when compared to the untethered case. This indicates the importance of considering surrounding medium in modelling of stent deployment, which however has often been neglected by modellers. This is also one of the limitations of this study. The interaction of the artery with its surrounding medium can be modelled explicitly by including the neighbouring tissues in the finite element model or by representing the tissues as spring-dashpot system attached to the arterial wall with the proper viscoelastic properties. We plan to take this into account in our future studies of the stent-artery system. According to published work (Liu et al., 2007; Kim et al., 2013), neglecting of surrounding tissues will make the artery less stiff and easier to deform, consequently leading to increased expansion during 
balloon inflation and reduced recoiling during deflation. To quantify such effect, a significant amount of new work needs to be carried out which is beyond the scope of the current paper. For the current work, the main objective was to understand the effect of different design, material choice and stent coating on the mechanical behaviour of stents during deployment. As long as the consistent environment was used, the generic conclusions should remain valid.

The artery considered in this study refers to a branch of coronary artery, such as left anterior descending, circumflex or left main coronary arteries. The length of those branches is usually no more than $20 \mathrm{~mm}$ (which is also the length used in this study), and it reduces even to 5-10mm when diseased (Gazetopoulos et al., 1976a; b). Consequently, the length of artery in our model was chosen to be comparable to that of coronary artery branch, and the branch was assumed to be fully constrained by neighbouring branches. To further understand the effect of the assumed constraint, simulation has been performed for an artery free of constraint. The results showed that boundary conditions impose little effect on the stent deformation during expansion stage, but affect the recoil effect and the final diameter. For artery free of constraint, reduced recoil (by $8 \%$ ) and increased final expansion (by 11\%) were obtained when compared to the fully constrained case. Furthermore, simulation has also been conducted for a longer artery (40mm, double the length used in the current work) which has the same constraints as that in the main study (i.e. fully constrained at the artery ends). The results showed a reduction of recoiling effect by about $6 \%$ and an increase of final expansion by $8 \%$, while the dogboning effect remained almost the same. From these studies, it is noted that different boundary conditions and artery lengths affect the simulation results. In this paper, the use of a short artery and fully constrained condition tends to generate amplified recoiling effect and underestimated final expansion. Again, as we aim to 
understand the effects of different design, material choice and stent coating on the mechanical behaviour of stents during deployment, the generic conclusions remain valid so long as the same condition was used throughout.

\section{Conclusions}

Effects of material choice and drug eluting coating on the expansion behaviour of stents have been studied based on finite element simulations of the full process of stent deployment inside a stenotic artery. At a given deployment pressure, more severe deformation, stronger dogboning/recoiling effects and considerably reduced residual stresses were observed for stents made of metallic materials with lower yield stress and weaker strain hardening Drug eluting coatings have limited effect on stent expansion as reflected by comparable diameter change, recoil/dogboning effects and residual stresses between coated and bare metal stents.

Comparative study of Palmaz-Schatz, Cypher, Xience and Endeavor stents confirmed that stent design is one of the major factors that control stent expansion. In particular, open-cell design (e.g. Endeavor) tends to expand more easily than closed-cell design (e.g. Cypher), but with higher recoiling effect. Dogboning effect can be reduced considerably for designs strengthened with longitudinal connective struts (e.g. Xience and Cypher). For all four stents, the maximum von Mises stresses appear to locate consistently at the U-bends of stent cell struts, with magnitudes depending on the materials and severity of plastic deformation.

The distribution and magnitude of stresses on the artery-plaque system appear to be largely influenced by the stent materials and designs. Closed-cell designs increase the radial stiffness of stents, and hence introduce strong interaction between stent and artery 
during stent deployment, leading to higher stress levels on the artery. While stents made of materials with low yield stress and weak strain hardening soothed the mechanical interaction between stent and artery, leading to stress reduction on the plaque.

Stent deployment also strongly depends on the composition of the stenotic plaque. The finally achieved expansion for calcified plaque is considerably lower than that for hypocellular plaque, which is the case for all four types of stent designs. In addition, the stresses in the plaque-artery system imply that stents with open cell design are less likely to cause plaque rupture, regardless of the plaque composition, due to the lower stress level on the plaque when compared to stents with closed cell design.

\section{References}

ABAQUS, 2013, Version 6.12, Dassault Systèmes, Vélizy-Villacoublay, France.

Adlakhna S., Sheikh M., Bruhl S., Eltahawy E., Pandya U., Colyer W., Cooper C., 2009. Coronary stent fracture: a cause of cardiac chest pain? International Journal of Cardiology 141, e23-e25.

Ali A., Hosseini M., Sahari B.B., 2010. A review of constitutive models for rubber-like materials. American Journal of Engineering and Applied Sciences 3, 232-239.

Celik T., Iyisoy A., Dogru M.T., Isik E., 2009. Coronary stent strut fracture after drug eluting stent implantation: a newly recognized complication. International Journal of Cardiology 132, 121-122.

Choe H., Hur G., Doh J.H., Namgung J., Lee S.Y., Park K.Y., Chang W.I., Lee W.R., 2009. A case of very late stent thrombosis facilitated by drug eluting stent fracture: comparative images before and after stent fracture detected by 64-multidetector computed tomography. International Journal of Cardiology 133, e125-e128. 
Chua S.N.D., 2002. Finite Element Modelling of the Expansion of Small Tubular Parts by Internal Pressure, Ph.D. Thesis, Dublin City University.

Chua S.N.D., McDonald B.J., Hashimi M.S.J., 2003. Finite element simulation of stent and balloon interaction. Journal of Material Processing Technology 143-144 591597.

Chua S.N.D., MacDonald B.J., Hashimi M.S.J., 2004. Finite element simulation of slotted tube (stent) with the presence of plaque and artery by balloon expansion. Journal of Material Processing Technology 155-156, 1772-1779.

Chung I.M., Gold H.K., Schwartz S.M., Ikari Y., Reidy M.A. and Wight T.N., 2002. Enhanced extracellular matrix accumulation in restenosis of coronary arteries after stent deployment. Journal American College Cardiology 40, 2072-2081.

Gastaldi D., Morlacchi S., Nichetti R., Capelli C., Dubini G., Petrini L., Migliavacca F., 2010. Modelling of the provisional side-branch stenting approach for the treatment of atherosclerotic coronary bifurcations: effects of stent positioning. Biomechanics and Modelling in Mechanobiology 9, 551-561

Gazetopoulos N., Ioannidis P. J., Karydis C., Lolas C., Kiriakou K., Tountas C., 1976. Short left coronary artery trunk as a risk factor in the development of coronary atherosclerosis pathological study, British Heart Journal 38, 1160-1165

Gazetopoulos N., Ioannidis P. J., Marselos A., Kelekis D., Lolas C., Avgoustakis D., Tountas C., 1976. Length of main left coronary artery in relation to atherosclerosis of its branches a coronary arteriographic study, British Heart Journal 38, 180-185

Gu L., Santra S., Mericle R.A., Kumar A.V., 2005. Finite element analysis of covered microstents. Journal Biomechanics 38, 1221-1227.

Gu L., Zhao S., Muttyam A.K. and Hammel J.M., 2010. The relation between the arterial stress and restenosis rate after coronary stenting. ASME Journal of Medical Devices 4, 031005-1. 
Haga J.H., Li Y.--J., Chien S., 2007. Molecular basis of the effects of mechanical stretch on vascular smooth muscle cells. Journal of Biomechanics 40, 947-960.

Hanawa T., 2009. Materials for metallic stents. Journal of Artificial Organs 12, 73-79.

Holzapfel G.A., Sommer G., Gasser C.T., Regitnig P., 2005. Determination of layerspecific mechanical properties of human coronary arteries with nonatherosclerotic intimal thickening and related constitutive modelling. American Journal of Physiology - Heart and Circulatory Physiology 289, 2048-2058.

Hopkins C.G., McHugh P.E., McGarry J.P., 2010. Computational investigation of the delamination of polymer coatings during stent deployment. Annals of Biomedical Engineering 38, 2263-2273.

Ju F., Xia Z., Sasaki K., 2008. On the finite element modelling of balloon-expandable stents. Journal of Mechanical Behaviour of Materials 1, 86-95.

Karimi A.,Navidbakhsh M., Faghihi S., 2014. A comparative study on plaque vulnerability using constitutive equations. Perfusion 29, 178-83

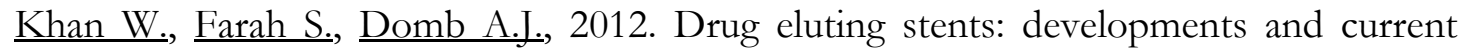
status. Journal of Controlled Release 161, 703-712.

Kim H.S., Kim Y.H., Lee S.W., Park D.W., Lee C.W., Hong M.K., Park S.W., Ko J.K., Park J.H., Lee J.H., Choi S.W., Seong I.W., Cho Y.H., Lee N.H., Kim J.H., Chun K.J., Park S.J., 2009. Incidence and predictors of drug-eluting stent fractures in long coronary disease. International Journal of Cardiology 133, 354-358.

Kim J., Peruski B., Hunley C., Kwon S., Baek S., 2013. Influence of surrounding tissues on biomechanics of aortic wall. International Journal of Experimental and Computational Biomechanics 2, 105-117.

Kleinstreuer C., Li Z., Basciano C.A., Seelecke S., Farber M.A., 2008. Computational mechanics of Nitinol stent grafts. Journal of Biomechanics 41, 2370-2378. 
Lally C., Dolan F., Prendergast P.J., 2005. Cardiovascular stent design and vessel stresses: a finite element analysis. Journal of Biomechanics 38, 1574-1581.

Liu Y., Dang C., Garcia M., Gregersen H., Kassab G.S., 2007. Surrounding tissues affect the passive mechanics of the vessel wall: theory and experiment. American Journal of Physiology - Heart and Circulatory Physiology 293, H3290-H3300.

Loree H.M., Grodzinsky A.J., Park S.Y., Gibson L.J., Lee R.T., 1994. Static circumferential tangential modulus of human atherosclerotic tissue. Journal of Biomechanics 27, 195-204.

Migliavacca F., Petrini L., Montanari V., Quagliana I., Auricchio F., Dubini G., 2005. A predictive study of the mechanical behaviour of coronary stents by computer modelling. Medical Engineering and Physics 27, 13-18.

Möller D., Reimers W., Pyzalla A., Fischer A., 2001. Residual stresses in coronary artery stents. Journal of Biomedical Materials Research 58, 69-74.

Mooney M., 1940. A theory of large elastic deformation. Journal of Applied Physics 11, $582-592$.

Okamura T., Hiro T., Fujii T., Yamada J., Fukumoto Y., Hashimoto G., Fujimura T., Yasumoto K., Matsuzaki M., 2008. Late giant coronary aneurysm associated with a fracture of sirolimus eluting stent: a case report. Journal of Cardiology 51, 74-79.

Park J.S., Shin D.G., Kim Y.J., Hong G.R., Cho I.H., 2009. Acute myocardial infarction as a consequence of stent fracture and plaque rupture after sirolimus eluting stent implantation. International Journal of Cardiology 134, e79-e81.

Pericevic I., Lally C., Toner D., Kelly D.J., 2009. The influence of plaque composition on underlying arterial wall stress during stent expansion: The case for lesion-specific stents. Medical Engineering and Physics 31, 428-433. 
Poncin P., Proft J., 2004. Stent tubing: understanding the desired attributes. Medical Device Materials: Proceedings of the Materials \& Processes for Medical Devices Conference 2003, 253-259.

Prendergast P.J., Lally C., Daly S., Reid A.J., Lee T.C., Quinn D., Dolan F., 2003. Analysis of prolapse in cardiovascular stents: a constitutive equation for vascular tissue and finite-element modelling. Journal of Biomechanical Engineering 125, 692699.

Rivlin R.S., 1948. Large elastic deformations of isotropic materials. IV. Further developments of the general theory. Philosophical Transactions of the Royal Society of London Series A 241, 379-397.

Sangiorgi G., Melzi G., Agostoni P., Cola C., Clementi F., Romitelli P., Virmani R., Colombo A., 2007. Engineering aspects of stents design and their translation into clinical practice. Annali dell'Istituto Superiore di Sanità 43, 89-100.

Shankaran K., Karrupaswamy S., 2012. Parameterization and optimization of balloon expandable Stent, 2012 3DS Simulia Community Conference, May 15-17, 2012, Rhode Island Convention, Providence, RI, USA.

Timmins L.H., Miller M.W., Clubb Jr. F.J., Moore Jr. J.E., 2011. Increased artery wall stress post-stenting leads to greater intimal thickening. Laboratory Investigation 91, $955-967$.

Umeda H., Gochi T., Iwase M., Izawa H., Shimizu T., Ishiki R., Inagaki H., Toyama J., Yokota M., Murohara T., 2009. Frequency, predictors and outcome of stent fracture after sirolimus-eluting stent implantation. International Journal of Cardiology 133, 321-326.

Walke W., Paszenda Z., Filipiak J., 2005. Experimental and numerical biomechanical analysis of vascular stent. Journal of Materials Processing Technology 164-165, $1263-1268$. 
Wu W., Petrini L., Gastaldi D., Villa T., Vedani M., Lesma E., Previtali B., Migliavacca F., 2010. Finite element shape optimization for biodegradable magnesium alloy stents. Biomedical Engineering Society 38, 2829-2840.

Zahedmanesh H., Kelly D.J., Lally C., 2010. Simulation of a balloon expandable stent in a realistic coronary artery - Determination of the optimum modelling strategy. Journal of Biomechanics 43, 2126-2132.

Zahedmanesh, H., Lally, C., 2009. Determination of the influence of stent strut thickness using the finite element method: implications for vascular injury and in-stent restenosis. Medical and Biological Engineering and Computing 47, 385-393.

Zhao S., Gu L. and Froemming S.R., 2012. Effects of arterial strain and stress in the prediction of restenosis risks: computer modelling of stent trials. Biomedical Engineering

Letters

2 ,

158-163. 


\section{Figure Captions}

Figure 1, Finite element mesh for Xience stent and stenotic artery (with balloon).

Figure 2, Material behaviour for (a) stainless steel (SS) 316L, Co-Cr L605 and Mg alloy AZ31; (b) stenotic plaque and the three layers of the artery.

Figure 3, (a) Diameter change for both stent and artery during stent deployment; (b) Evolution of dogboning and recoiling during deflation.

Figure 4, Diameter change of stent during its deployment inside a stenotic artery using single inflation and multiple inflations methods.

Figure 5, Effect of material choice on (a) stent expansion and (b) stent recoiling and dogboning.

Figure 6, The von Mises stresses on the stents, made of different materials, after stent deployment.

Figure 7, Effect of drug eluting coating on (a) stent expansion and (b) stent recoiling and dogboning.

Figure 8, The von Mises stresses on bare metal Xience stent and coated Xience stent after stent deployment. 
Figure 9, Comparison of (a) stent expansion and (b) recoiling and dogboning effects for four types of stents with distinctly different designs.

Figure 10, The von Mises stresses on the Palmaz-Schatz, Cypher, Xience and Endeavor stents after deployment.

Figure 11, Effect of material choice on the von Mises stresses on the plaque/artery following stent deployment.

Figure 12, Effect of coating on the von Mises stresses on stenotic blood vessel following stent deployment.

Figure 13, The von Mises stresses on stenotic blood vessel expanded with PalmazSchatz, Cypher, Xience and Endeavor stents, respectively.

Figure 14, Stress-strain behaviour for hypocellular and calcified plaques (Ogden model).

Figure 15, Simulated stent expansion for four types of stents using the calcified plaque model.

Figure 16, Comparison of the maximum von Mises stresses on the calcified and hypocellular plaques for four different stent designs after deployment. 


\section{Table Captions}

Table 1, Bilinear properties for the phosphorylcholine (PC) polymer coating (Hopkins et al., 2010).

Table 2, Coefficients of the Mooney-Rivlin model used to describe the behaviour of the polyurethane balloon (Chua et al., 2004).

Table 3, Coefficients of the Ogden model used to describe the material behaviour of the three vessel wall layers and the hypocellular stenotic plaque (Zahedmanesh and Lally, 2009).

Table 4, Coefficients of the Ogden model used to describe the material behaviour of the calcified stenotic plaque. 


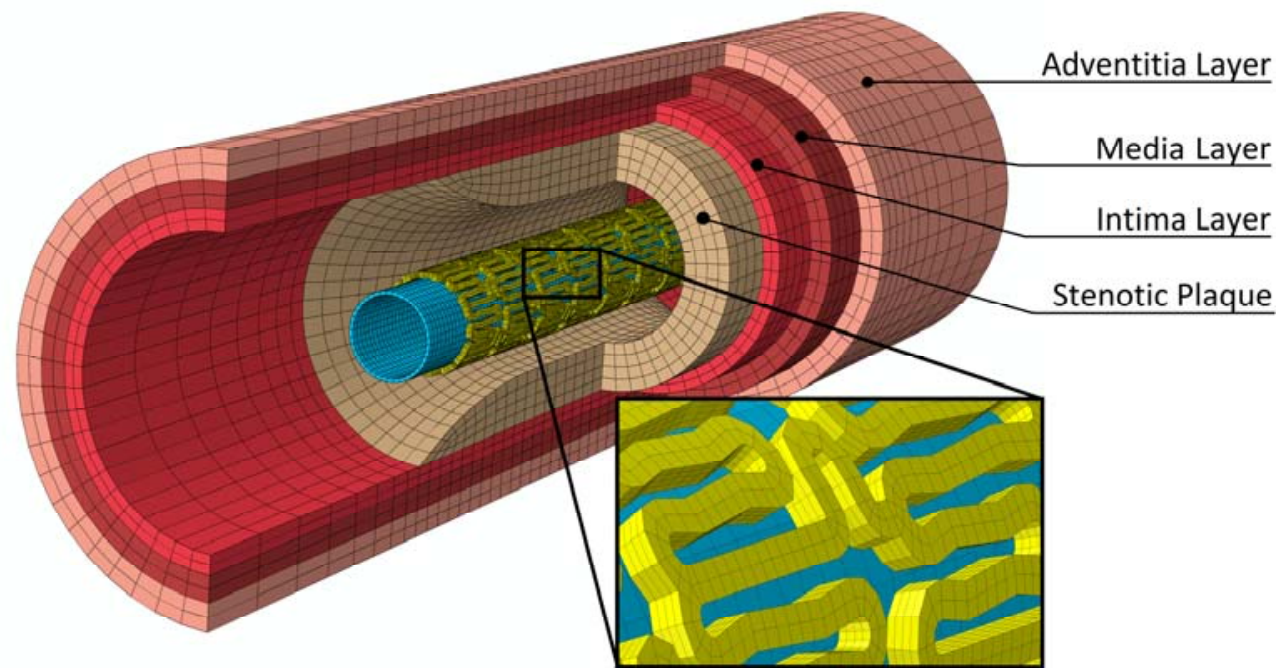

Figure 2, Finite element mesh for balloon, Xience stent and stenotic artery. 


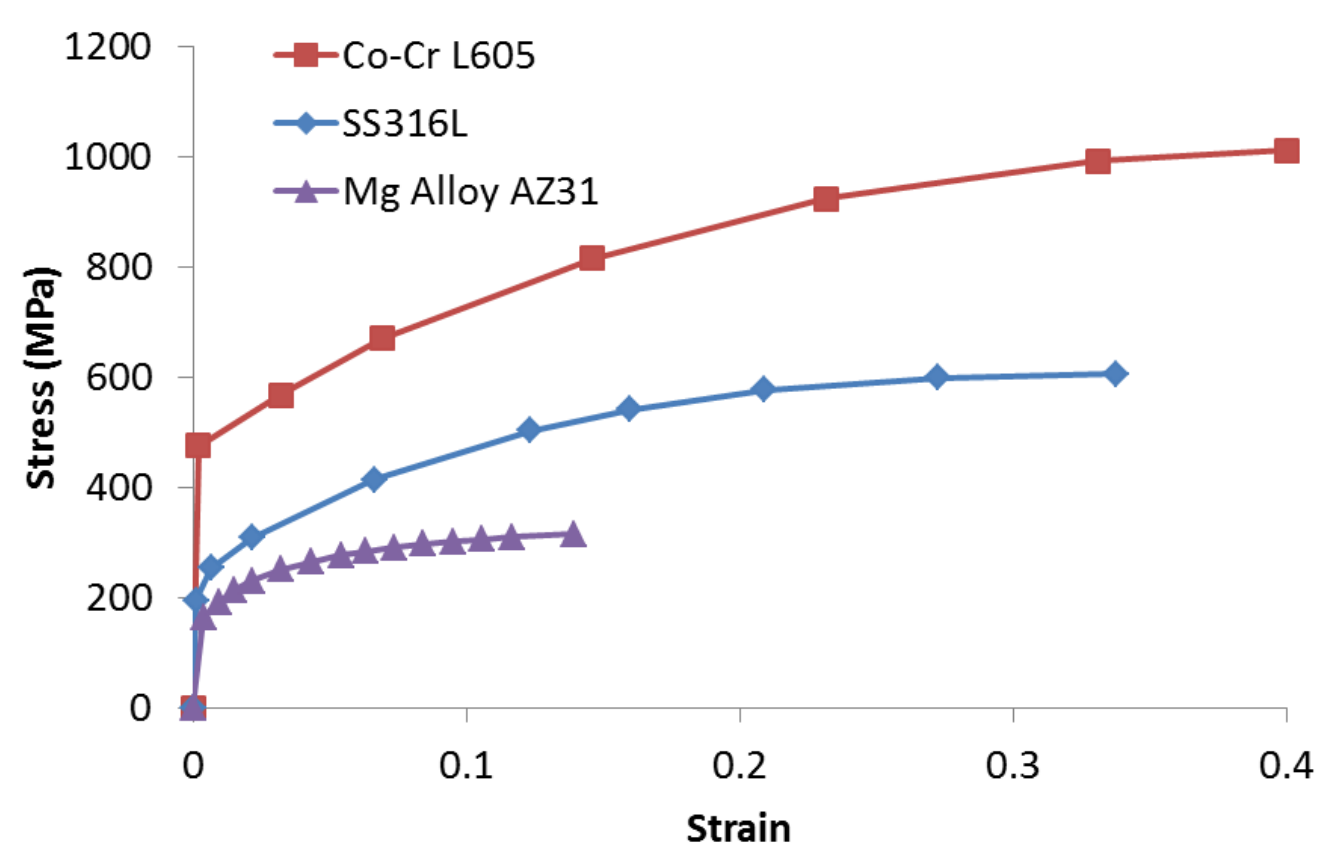

(a)

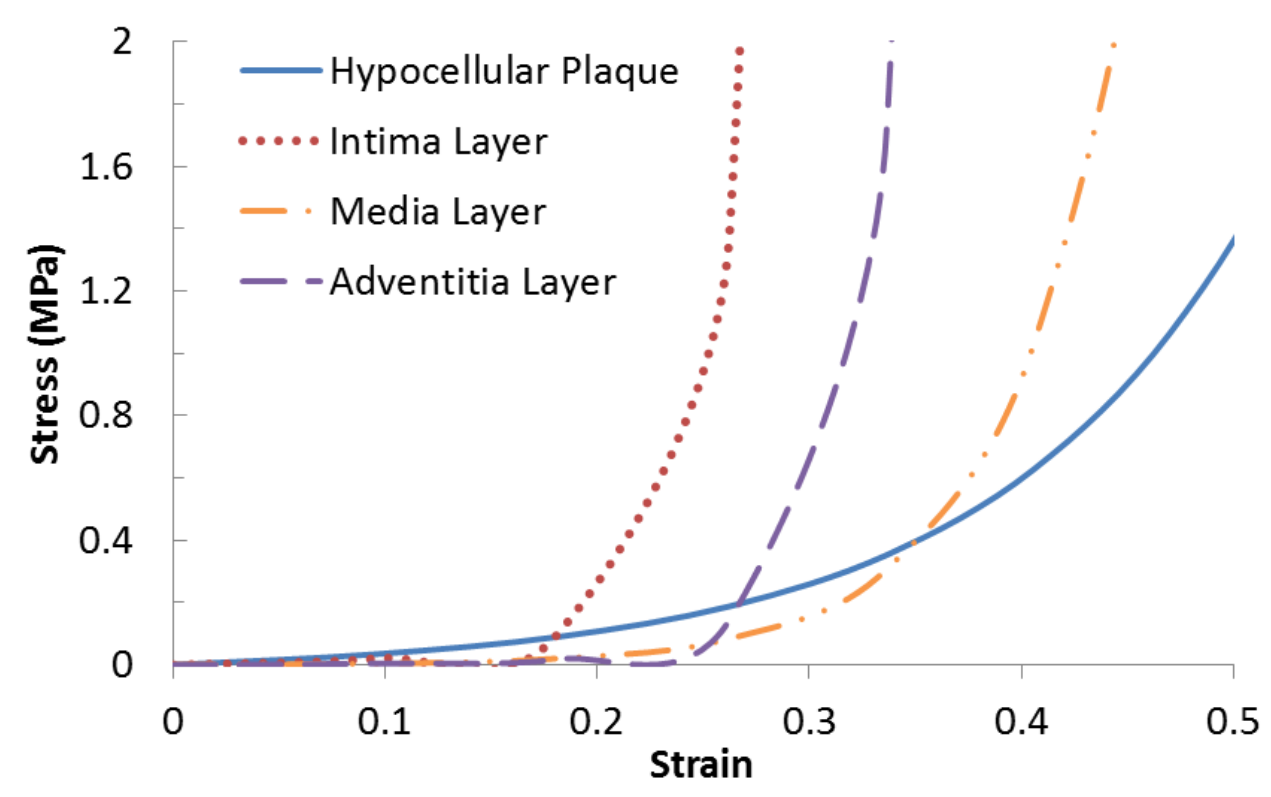

(b)

Figure 2, Material behaviour for (a) stainless steel (SS) 316L, Co-Cr L605 and Mg alloy AZ31; (b) stenotic plaque and the three layers of the artery. 


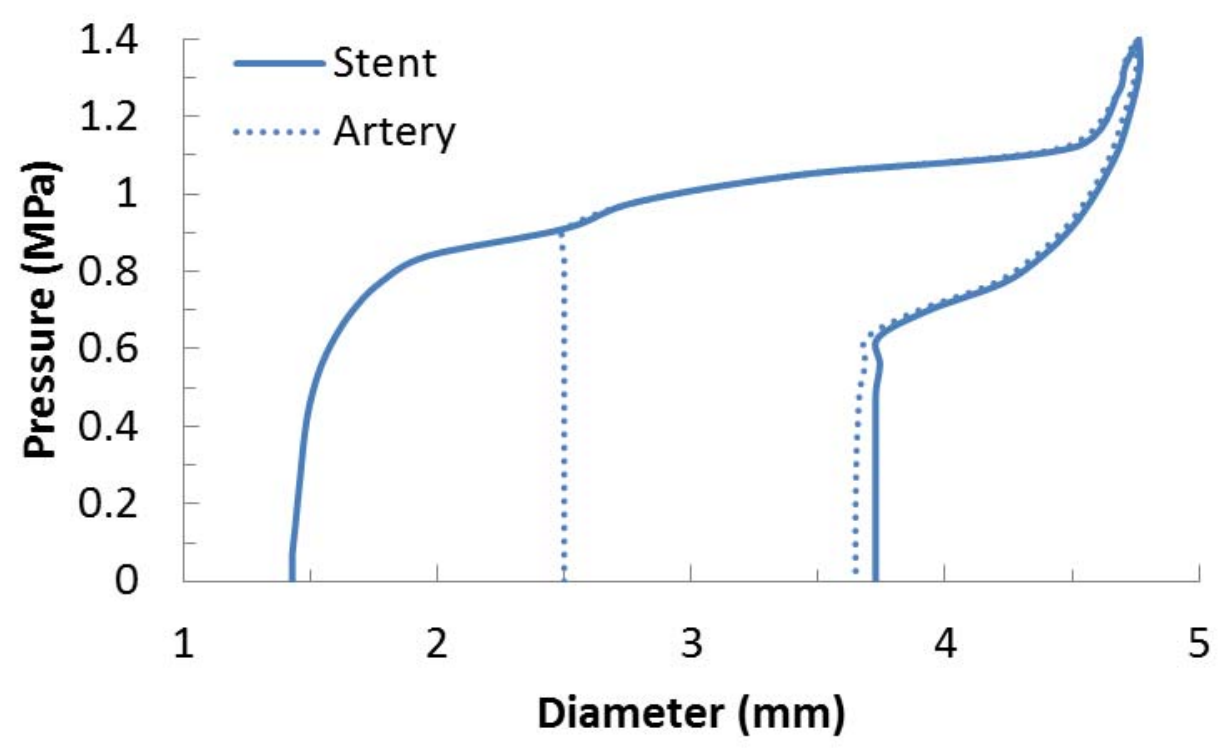

(a)

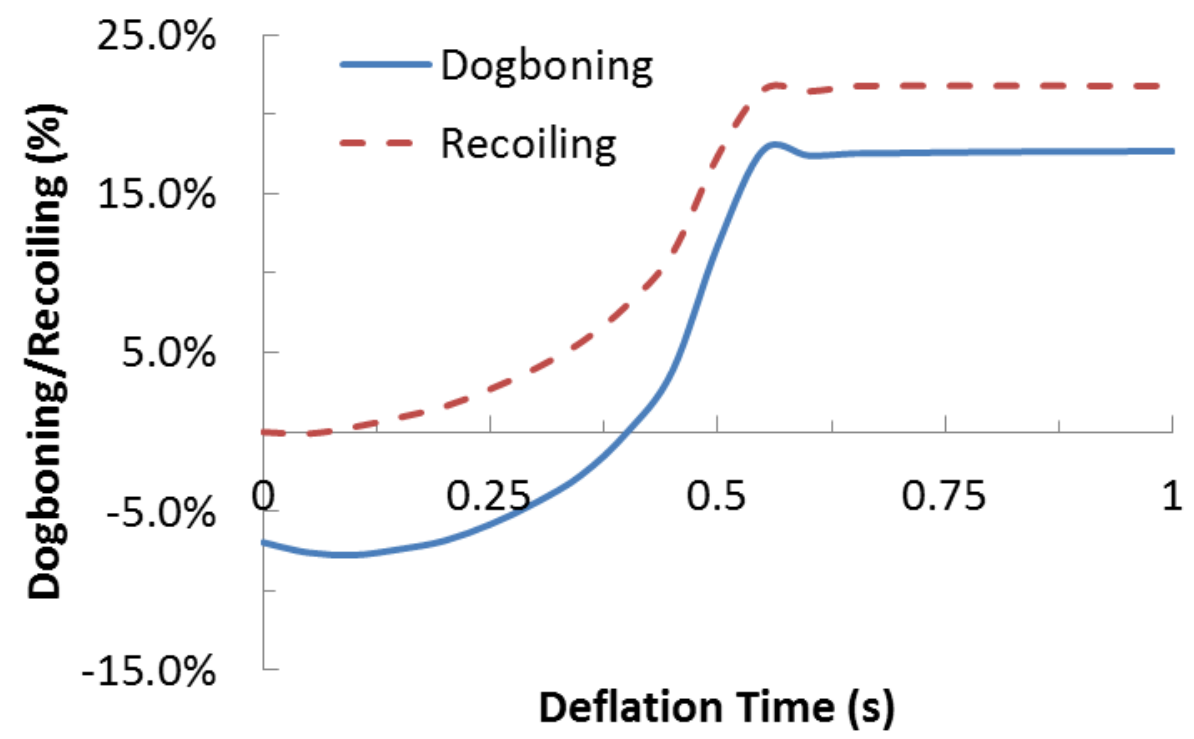

(b)

Figure 3, (a) Diameter change for both stent and artery during stent deployment; (b)

Evolution of dogboning and recoiling during deflation. 


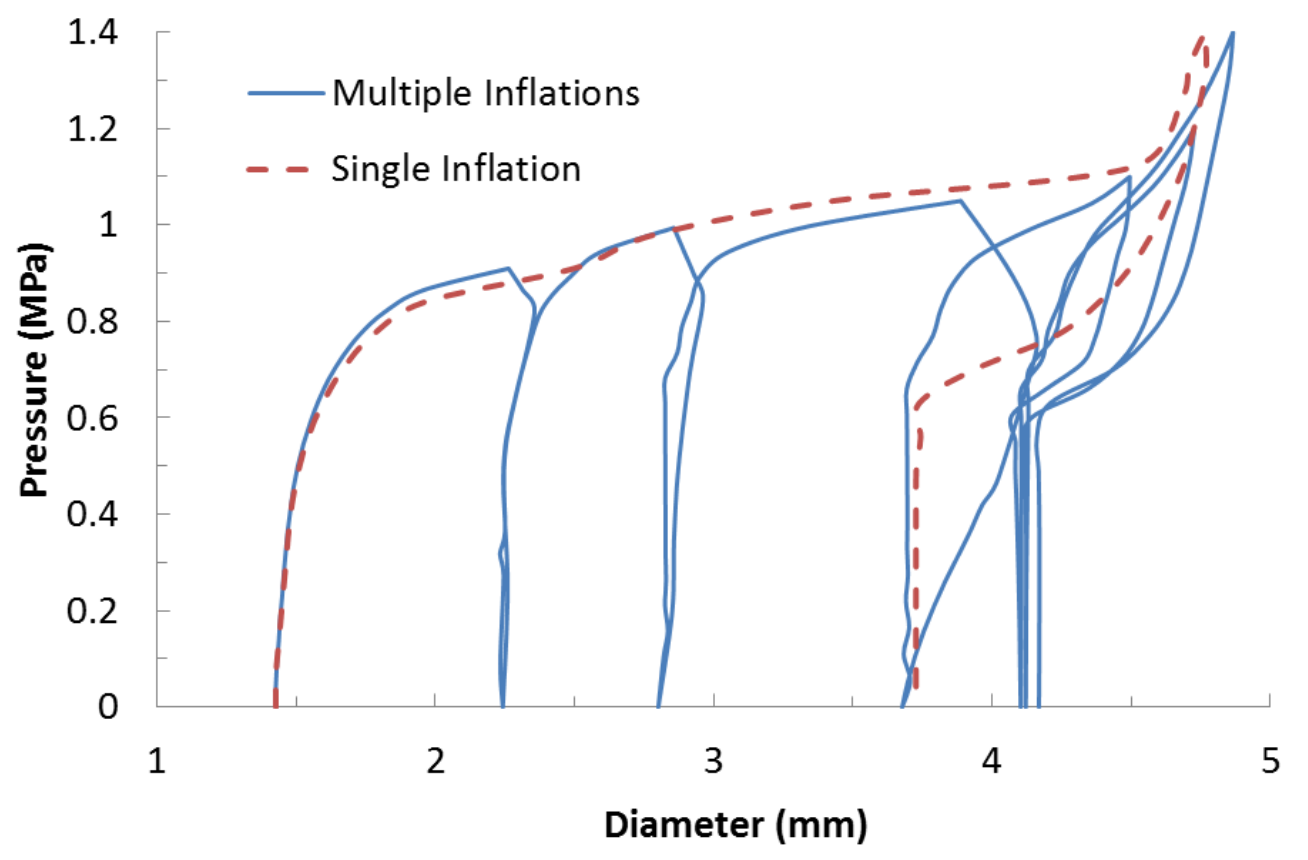

Figure 4, Diameter change of stent during its deployment inside a stenotic artery using single inflation and multiple inflations methods. 


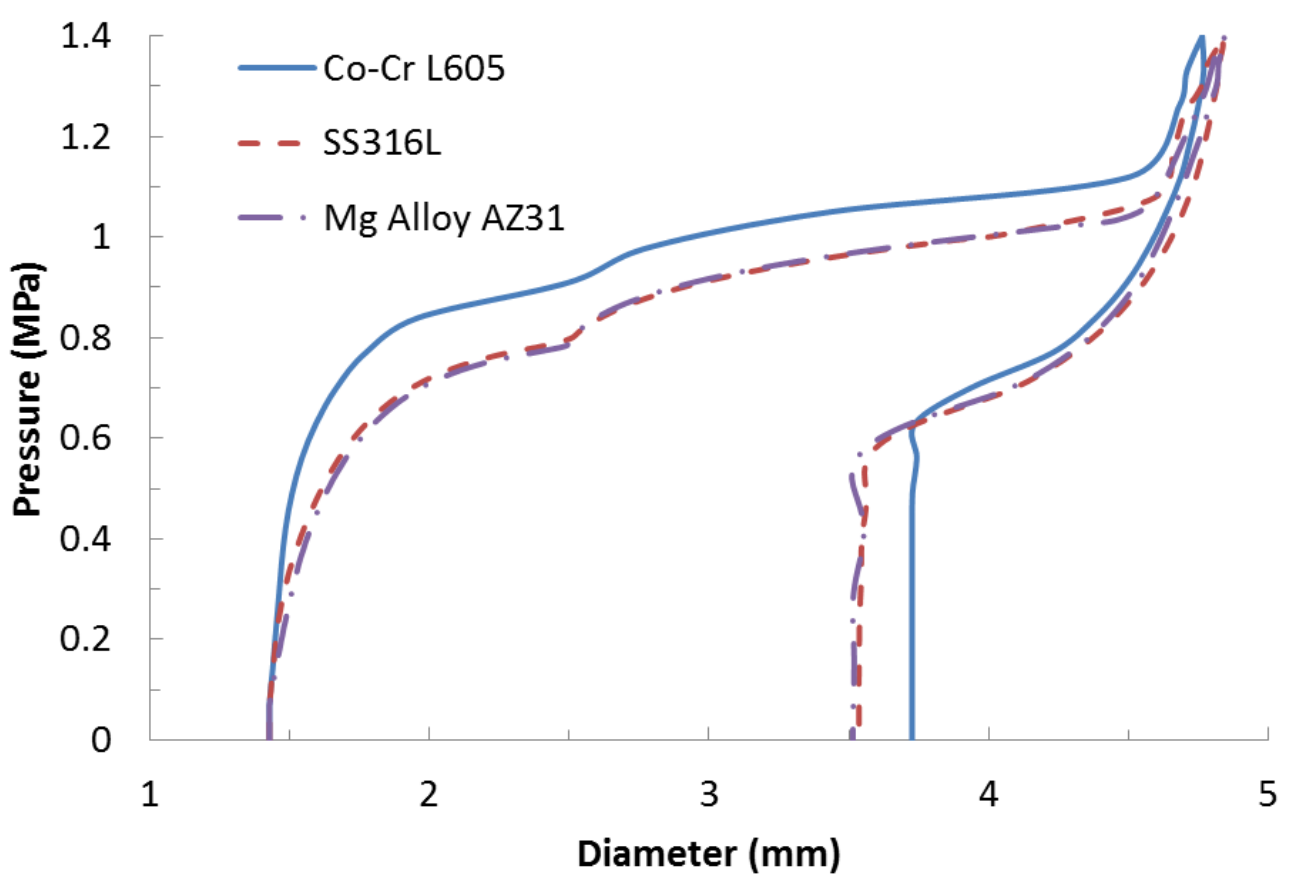

(a)

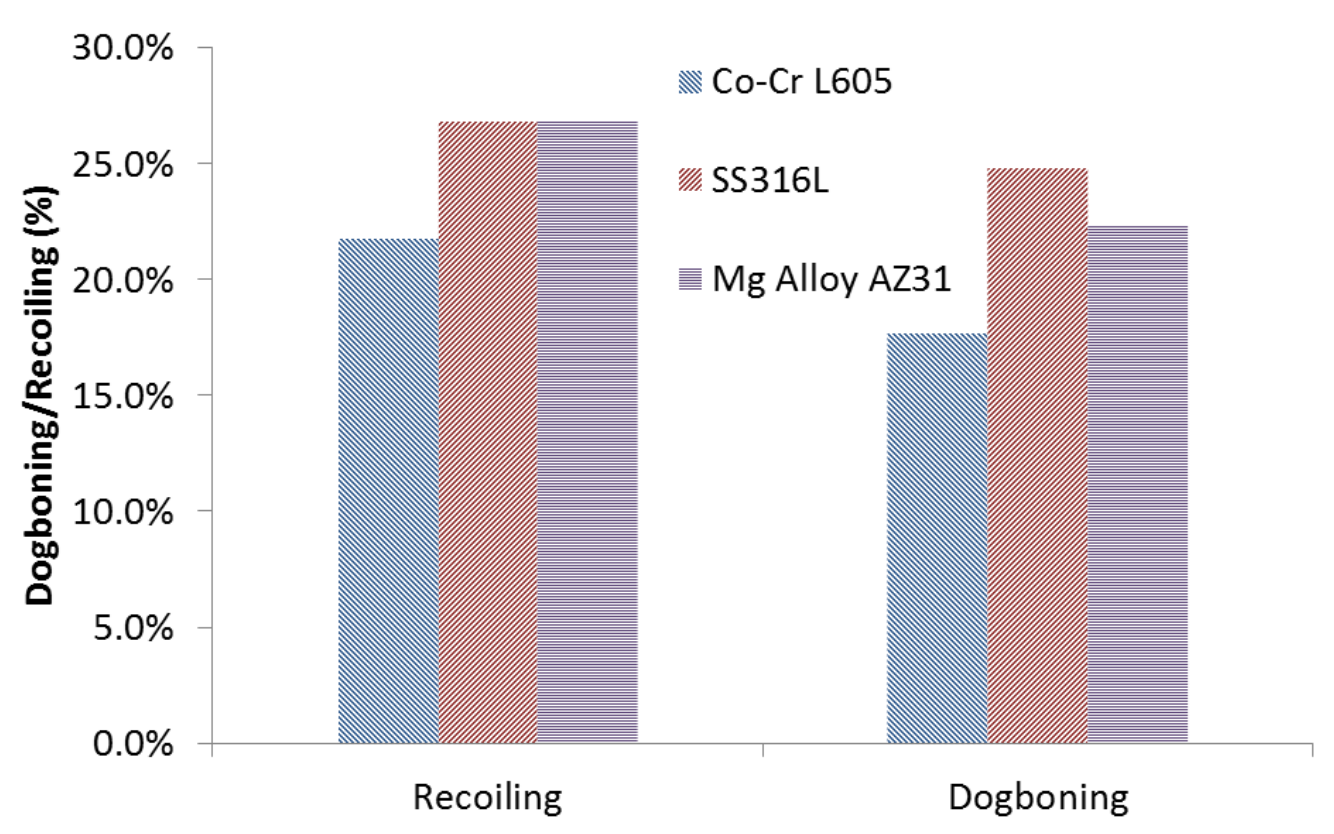

(b)

Figure 5, Effect of material choice on (a) stent expansion and (b) stent recoiling and dogboning. 
SS316L

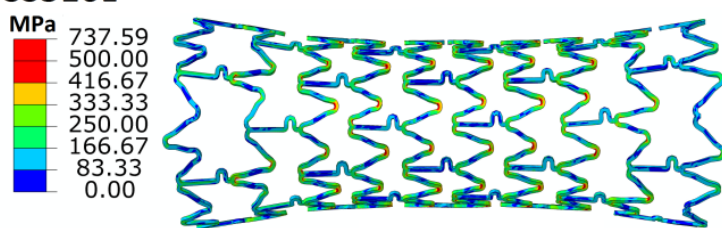

Co-Cr L605

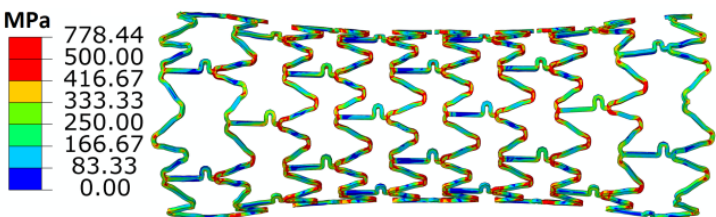

Figure 6, The von Mises stresses on the stents, made of different materials, after deployment.

Mg Alloy AZ31

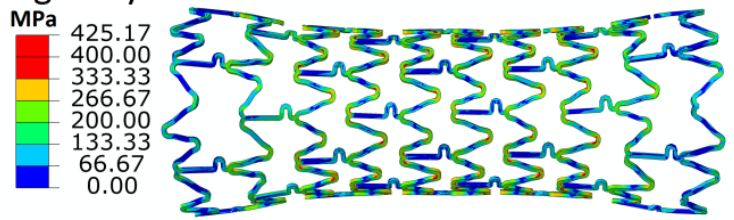




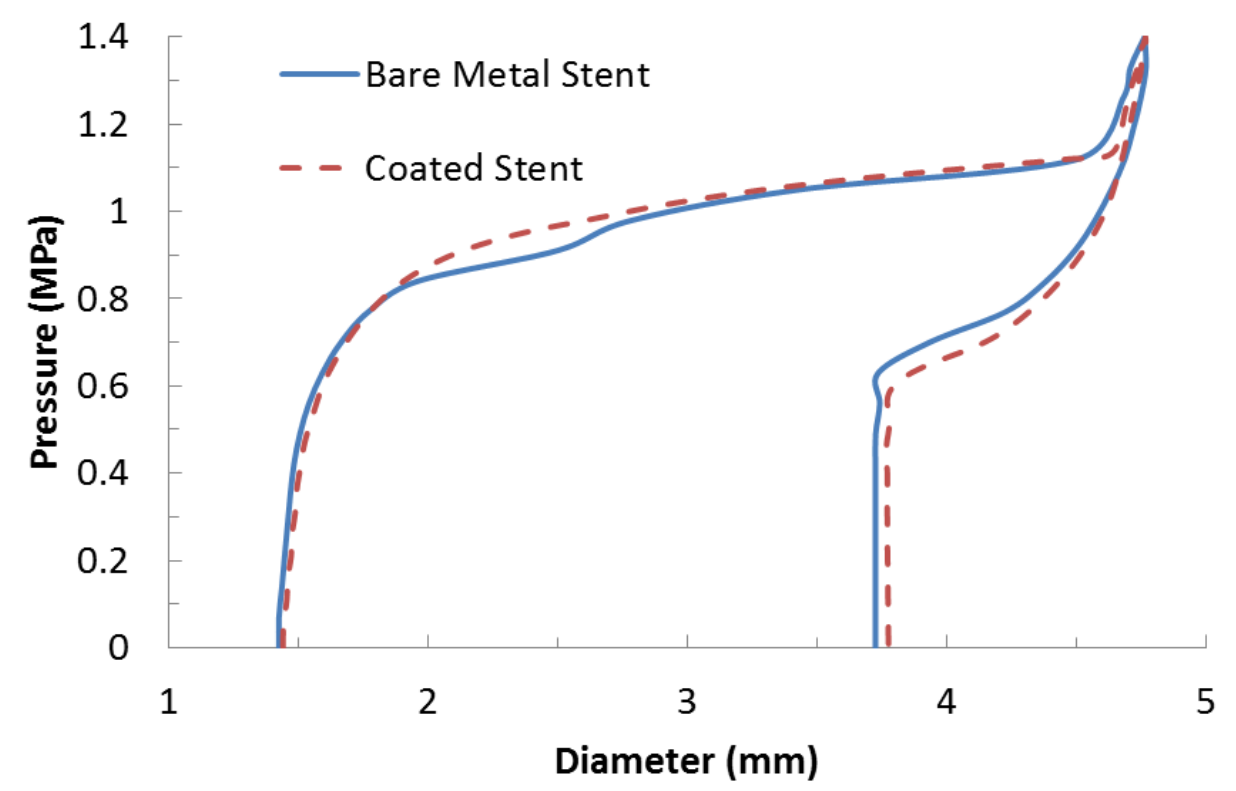

(a)

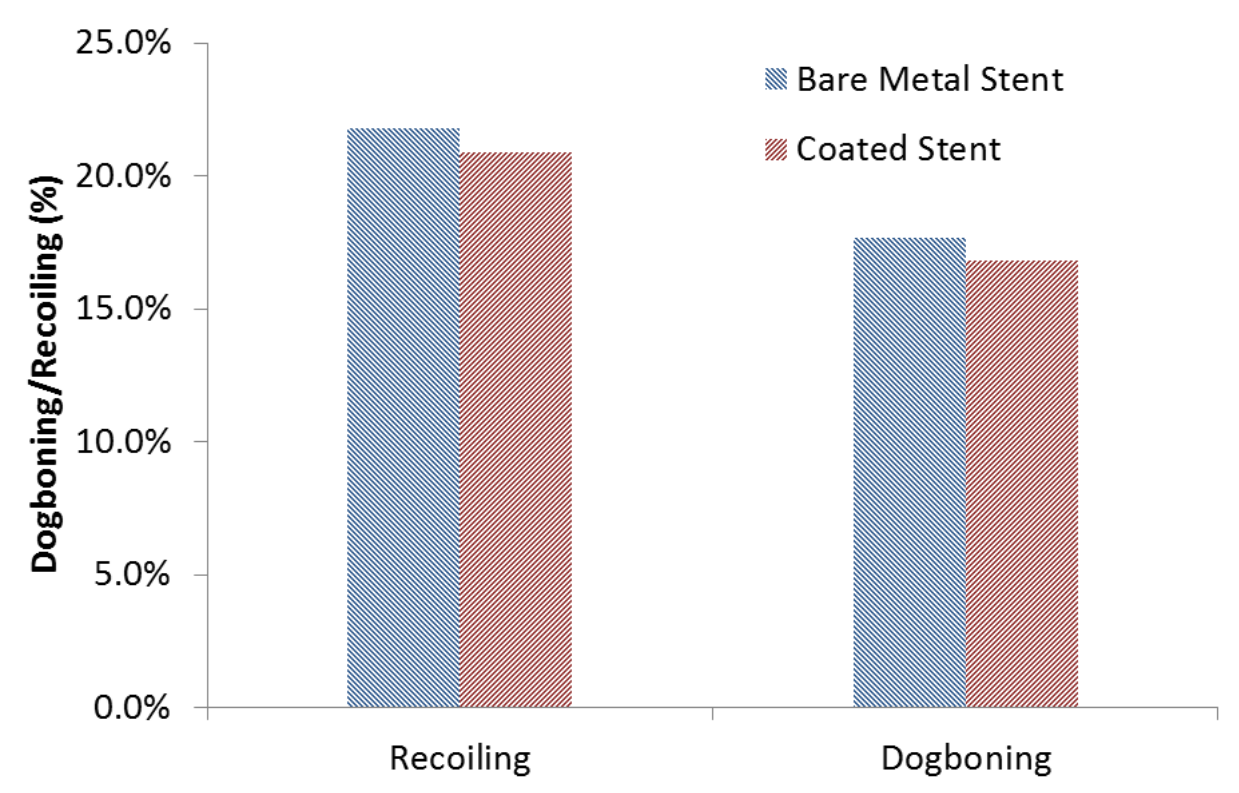

(b)

Figure 7, Effect of drug eluting coating on (a) stent expansion and (b) stent recoiling and dogboning. 

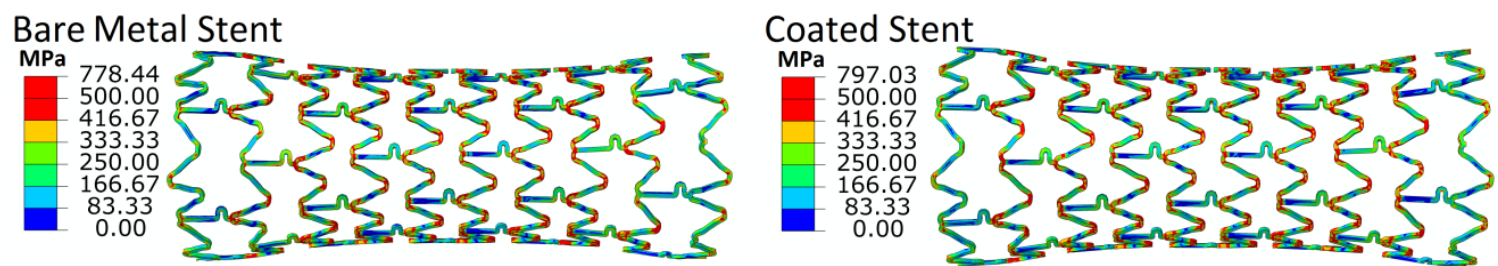

Figure 8, The von Mises stresses on bare metal Xience stent and coated Xience stent after stent deployment. 


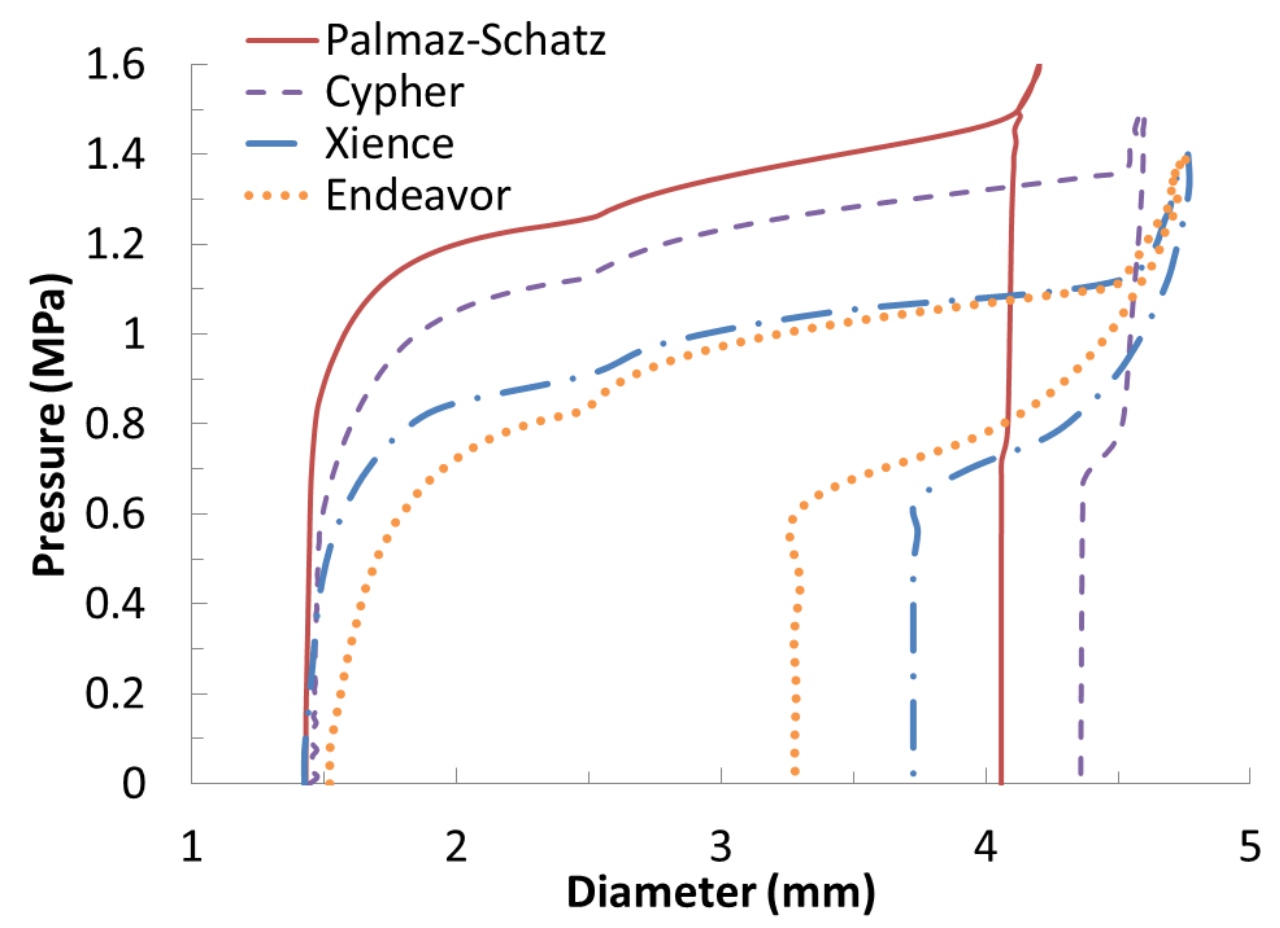

(a)

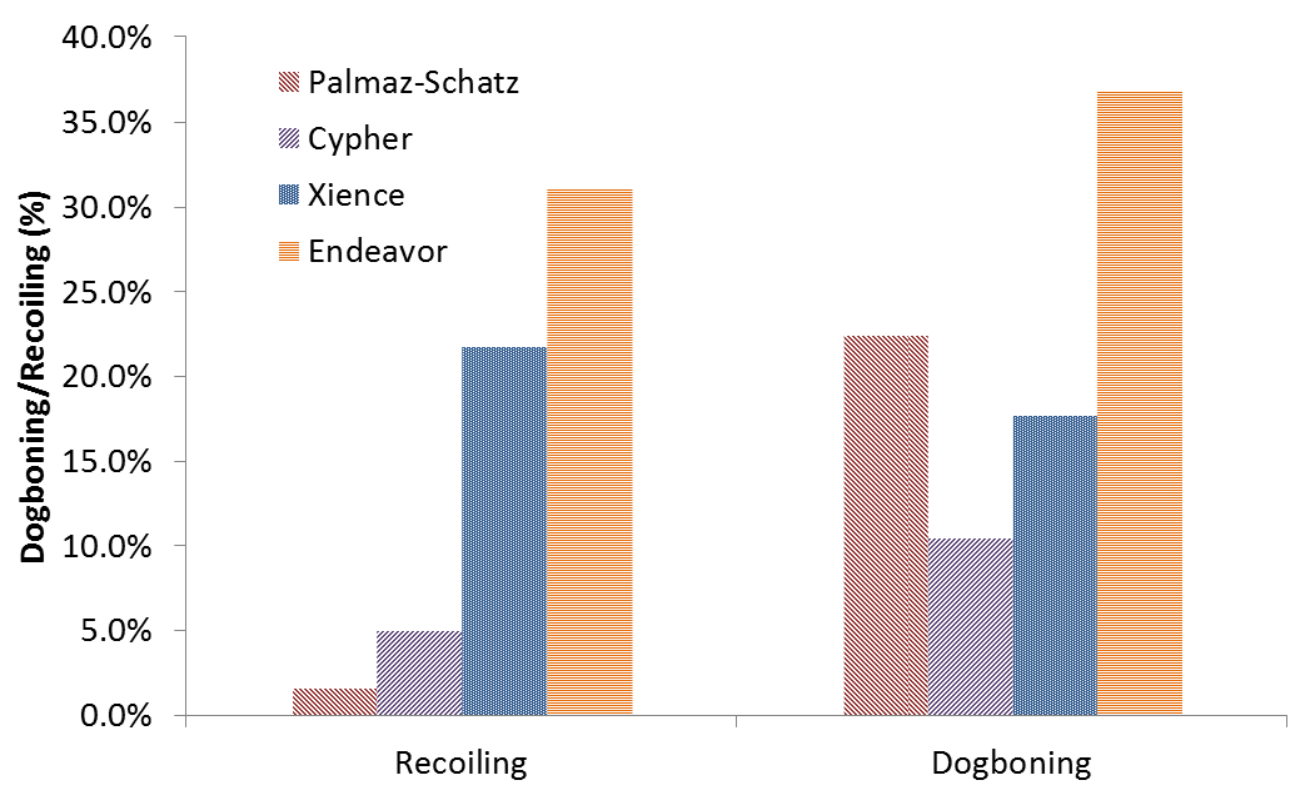

(b)

Figure 9, Comparison of (a) stent expansion and (b) recoiling and dogboning effects for four types of stents with distinctly different designs. 
Palmaz-Schatz

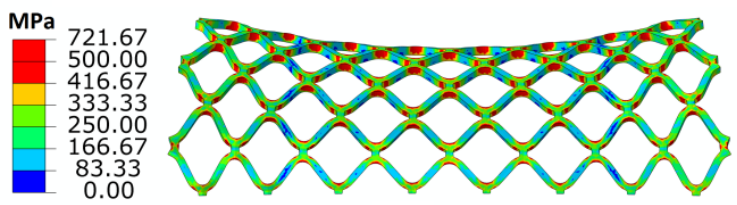

Xience

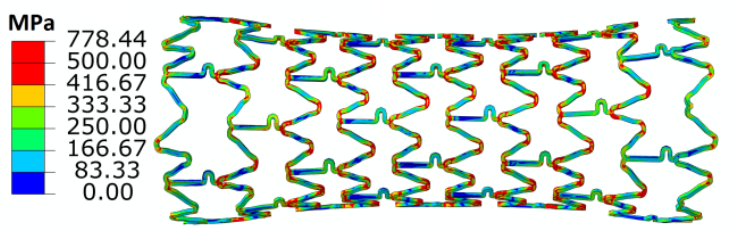

Cypher

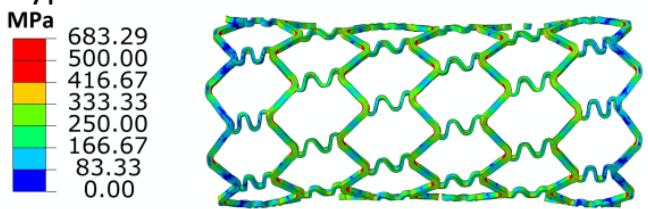

Endeavor

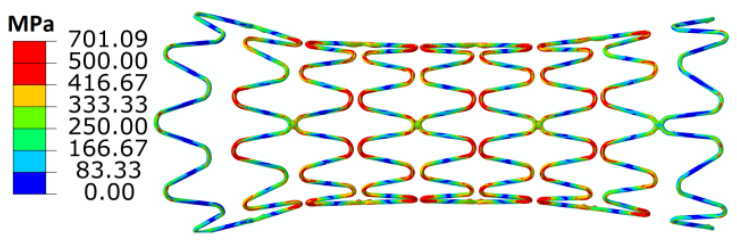

Figure 10, The von Mises stresses on the Palmaz-Schatz, Cypher, Xience and Endeavor stents after deployment.

SS316L

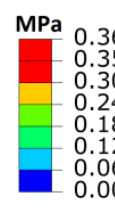

Mg Alloy AZ31

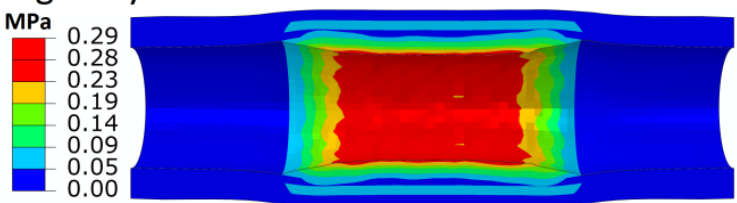

Co-Cr L605

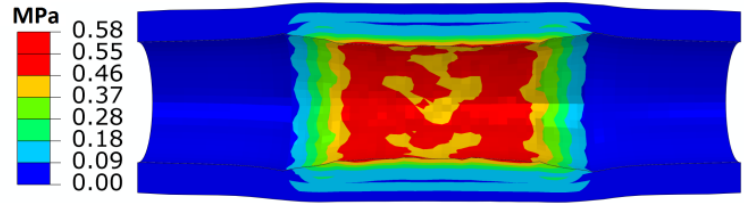

Figure 11, Effect of material choice on the von Mises stresses on the plaque/artery following stent deployment. 
Bare Metal Stent

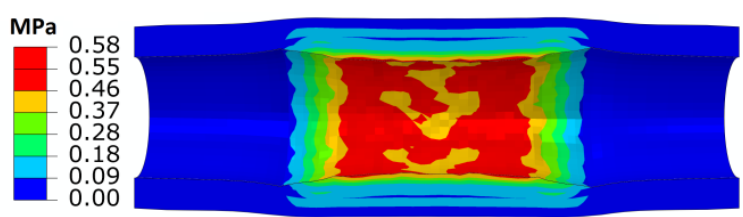

\section{Coated Stent}

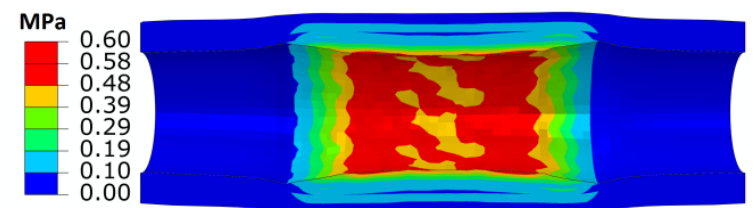

Figure 12, Effect of coating on the von Mises stresses on stenotic blood vessel following stent deployment.

Palmaz-Schatz

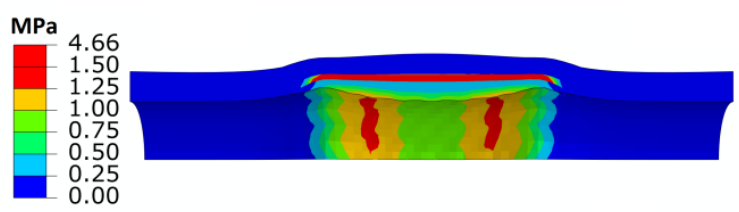

Xience

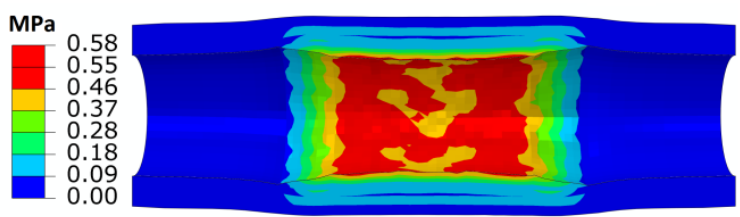

Cypher

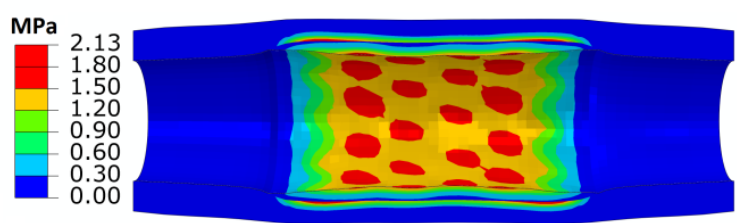

Endeavor

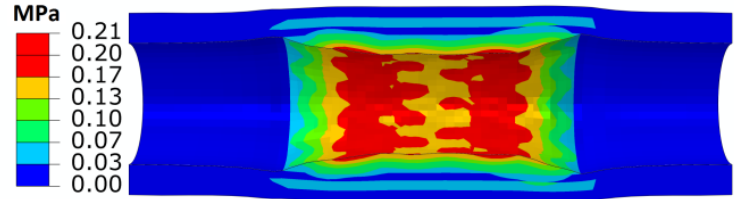

Figure 13, The von Mises stresses on stenotic blood vessel expanded with Palmaz-

Schatz, Cypher, Xience and Endeavor stents, respectively. 


\section{Ogden Model}

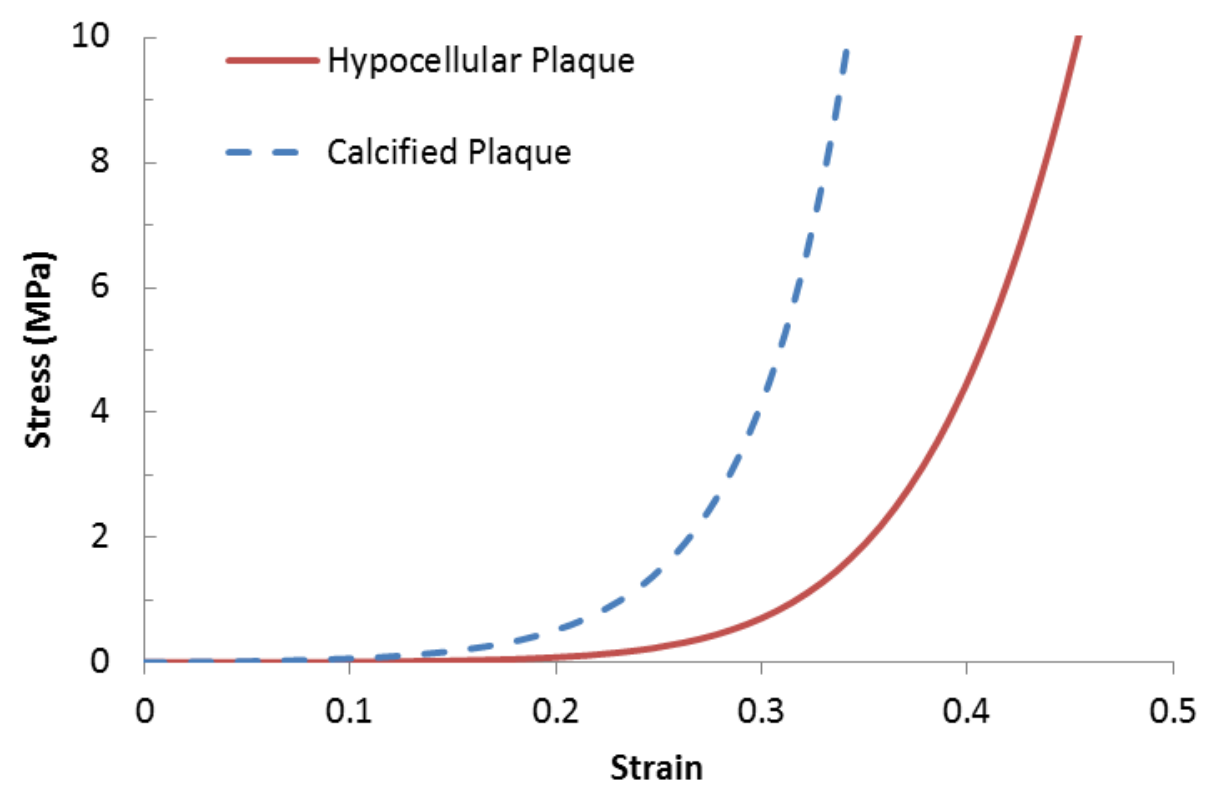

Figure 14, Stress-strain behaviour for hypocellular and calcified plaques (Ogden model). 


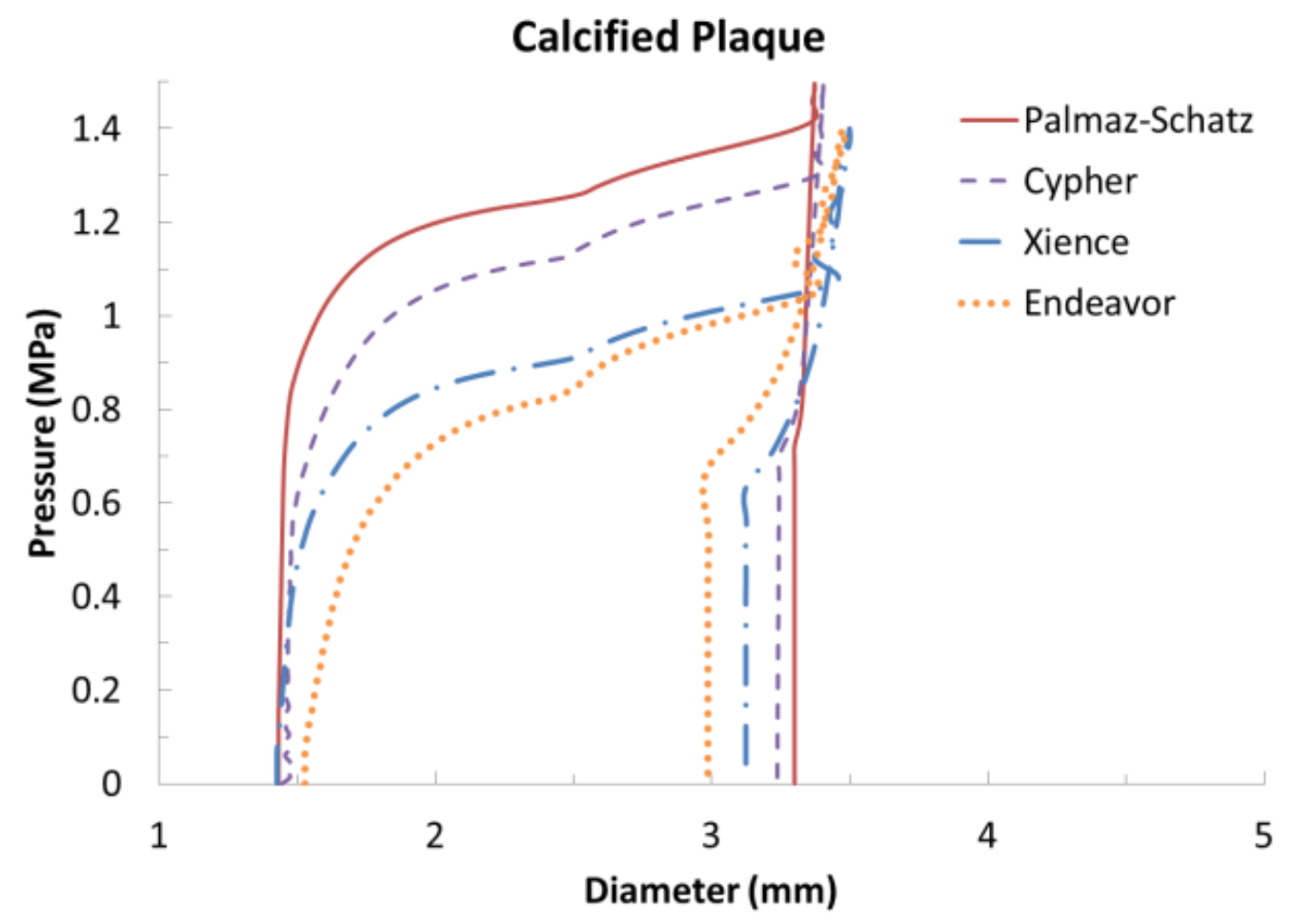

Figure 15, Simulated stent expansion for four types of stents using the calcified plaque model. 


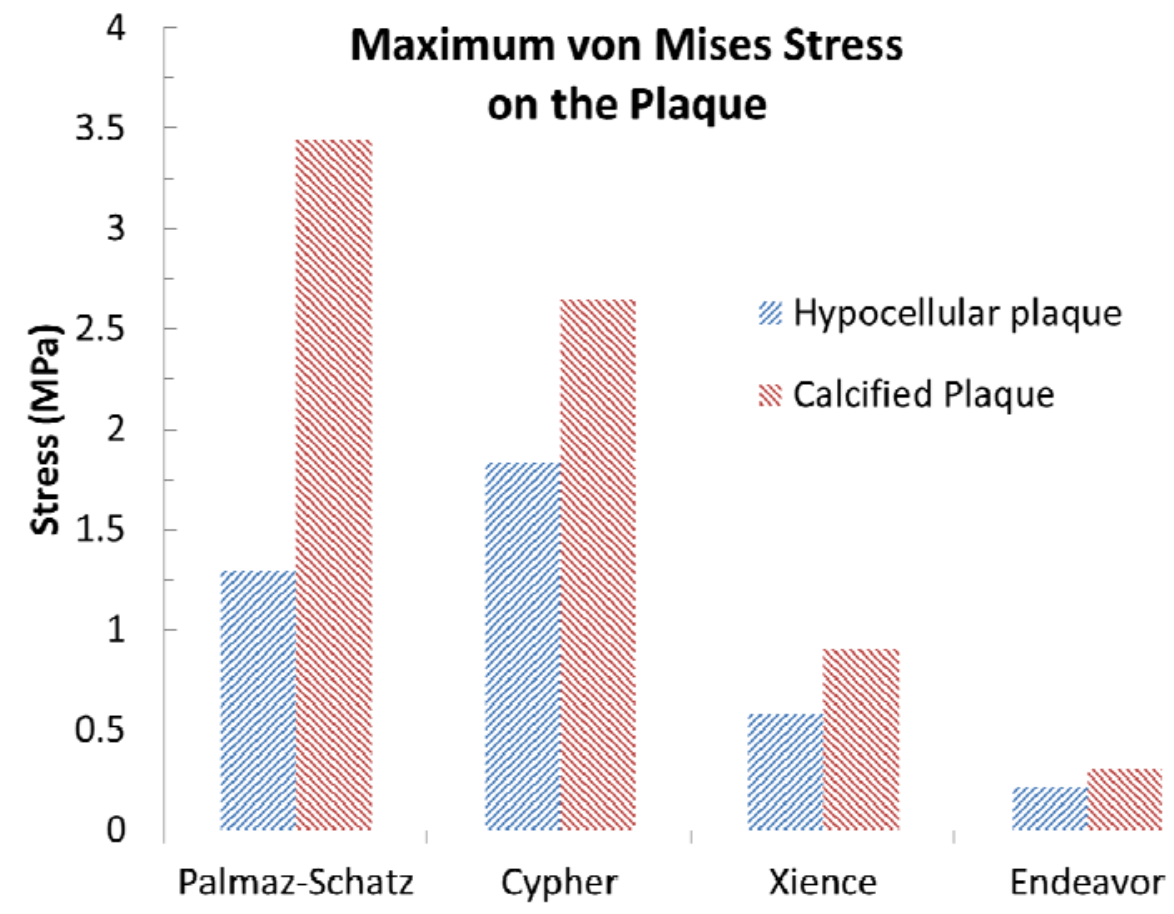

Figure 16, Comparison of the maximum von Mises stresses on the calcified and hypocellular plaques for the four stent designs following deployment. 
Table 1, Bilinear properties for the phosphorylcholine (PC) polymer coating (Hopkins et al., 2010).

\begin{tabular}{lccccc}
\hline Material & $\rho\left(\mathrm{kg} / \mathrm{mm}^{3}\right)$ & $\mathrm{E}(\mathrm{MPa})$ & $\nu$ & $\sigma_{\mathrm{y}}(\mathrm{MPa})$ & $\mathrm{E}_{\mathrm{t}}(\mathrm{MPa})$ \\
\hline PC polymer & $1.2 \cdot 10^{-6}$ & 240 & 0.5 & 16 & 7.7 \\
\hline
\end{tabular}


Table 2, Coefficients of the Mooney-Rivlin model used to describe the behaviour of the polyurethane balloon (Chua et al., 2004).

\begin{tabular}{lcccc}
\hline Material & $\rho\left(\mathrm{kg} / \mathrm{mm}^{3}\right)$ & $\mathrm{C}_{10}$ & $\mathrm{C}_{01}$ & $\mathrm{D}_{1}$ \\
\hline Polyurethane & $1.07 \cdot 10^{-6}$ & 1.03176 & 3.69266 & 0 \\
\hline
\end{tabular}


Table 3, Coefficients of the Ogden model used to describe the material behaviour of the three vessel wall layers and the hypocellular stenotic plaque (Zahedmanesh and Lally, 2009).

\begin{tabular}{lcccccccc}
\hline Material & $\rho\left(\mathrm{kg} / \mathrm{mm}^{3}\right)$ & $\mu_{1}$ & $\mu_{2}$ & $\mu_{3}$ & $\alpha_{1}$ & $\alpha_{2}$ & $\alpha_{3}$ & $D_{1}$ \\
\hline Intima & $1.066 \cdot 10^{-6}$ & -7.04 & 4.23 & 2.85 & 24.48 & 25.00 & 23.54 & $8.95 \cdot 10^{-7}$ \\
Media & $1.066 \cdot 10^{-6}$ & -1.23 & 0.88 & 0.45 & 16.59 & 16.65 & 16.5 & $5.31 \cdot 10^{-6}$ \\
Adventitia & $1.066 \cdot 10^{-6}$ & -1.28 & 0.85 & 0.44 & 24.63 & 25.00 & 23.74 & $4.67 \cdot 10^{-6}$ \\
& & & & & & & & \\
Plaque & $1.45 \cdot 10^{-6}$ & 0.093 & - & - & 8.17 & - & - & $4.30 \cdot 10^{-7}$ \\
& & & & & & & & \\
\hline
\end{tabular}


Table 4, Coefficients of the Ogden model used to describe the material behaviour of the calcified stenotic plaque.

\begin{tabular}{lcccc}
\hline Material & $\rho\left(\mathrm{kg} / \mathrm{mm}^{3}\right)$ & $\mu_{1}$ & $\alpha_{1}$ & $\mathrm{D}_{1}$ \\
\hline Calcified plaque & $1.45 \cdot 10^{-6}$ & 0.084 & 20.82 & $2.70 \bullet 10^{-7}$ \\
\hline
\end{tabular}

